\title{
Neck pain is the leading cause of disability burden in China: Findings from the Global Burden of Disease Study 2017
}

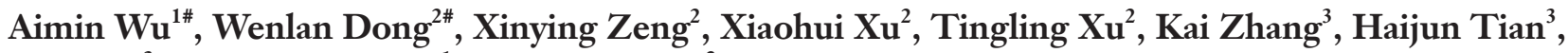 \\ Jie Zhao ${ }^{3}$, Xiangyang Wang ${ }^{1}$, Maigeng Zhou ${ }^{2}$ \\ ${ }^{1}$ Division of Spine Surgery, Department of Orthopedics, Zhejiang Spine Research Centre, Orthopedic Hospital, The Second Affiliated Hospital \\ and Yuying Children's Hospital of Wenzhou Medical University, Zhejiang Provincial Key Laboratory of Orthopedics, Wenzhou, China; ${ }^{2}$ National \\ Centre for Chronic and Noncommunicable Disease Control and Prevention, Chinese Centre for Disease Control and Prevention, Beijing, China; \\ ${ }^{3}$ Department of Orthopedics, Ninth People's Hospital, Shanghai Jiaotong University School of Medicine, Shanghai, China \\ Contributions: (I) Conception and design: A Wu, W Dong, M Zhou; (II) Administrative support: JZ, X Wang, M Zhou; (III) Provision of study \\ materials or patients: X Zeng, X Xu, T Xu, K Zhang, H Tian; (IV) Collection and assembly of data: A Wu, W Dong, X Zeng, X Xu, T Xu, K Zhang, \\ H Tian; (V) Data analysis and interpretation: A Wu, W Dong, X Zeng, X Xu, T Xu, J Zhao, X Wang, M Zhou; (VI) Manuscript writing: All authors; \\ (VII) Final approval of manuscript: All authors. \\ \#These authors contributed equally to this work as co-first authors. \\ Correspondence to: Maigeng Zhou, PhD. National Centre for Chronic and Noncommunicable Disease Control and Prevention, Chinese Centre for \\ Disease Control and Prevention, 27 Nanwei Rd, Xicheng District, Beijing 100050, China. Email: maigengzhou@126.com.
}

Background: Neck pain (NP) is a common musculoskeletal problem; however, the prevalence and years lived with disability (YLD) of NP in China are still unclear. This study sought to estimate the age-, sex- and province-specific prevalence and YLD of NP in China.

Methods: Adopting the methodology framework and analytical strategies used in the Global Burden of Disease (GBD), Injuries, and Risk Factors Study (2017), the prevalence and YLD of NP in China were estimated by age, sex, year, and provinces/regions.

Results: In China, the age-standardized point prevalence rate of NP was 4,532.6 per 100,000 persons in 1990 and increased slightly to 4,634.4 per 100,000 persons in 2017. The prevalence of NP was 48.0 million in 1990 and rose dramatically to 87.3 million in 2017 (an increase of 82.0\%). The age-standardized YLD rate of NP was 454.0 per 100,000 persons in 1990, and there was a slight increase to 465.6 per 100,000 persons in 2017. The all-age YLD of NP was 4.8 million in 1990 and rose to 8.8 million in 2017 (which represents an increase of $81.1 \%$ ). In 1990, NP was the third leading cause of YLD in China, and in 2017, NP was the leading cause of disability burden.

Conclusions: This study estimated the prevalence and disability burden of NP in China. NP is currently the leading cause of disability burden in China; however, it is currently inadequately recognized and should receive further attention and be subject to further research.

Keywords: Neck pain (NP); years lived with disability (YLD); disability burden; China

Submitted Oct 12, 2020. Accepted for publication Jan 29, 2021.

doi: $10.21037 / \mathrm{atm}-20-6868$

View this article at: http://dx.doi.org/10.21037/atm-20-6868

\section{Introduction}

Neck pain (NP) is a very common clinical condition (1-3). In 2010, the Global Burden of Disease (GBD) Study found that of 291 conditions, NP was the fourth leading condition in terms of disability burden (4). A recent study estimated that at $\$ 87.6$ billion [uncertainty interval (UI): $\$ 67.5-94.1$ billion] (USD), the annual cost of low back pain and NP represented the third-highest amount of healthcare spending, after diabetes and heart disease (5). Further, 
it has been reported that the risk of back pain and NP will surpass that of diabetes and heart disease (6). Thus, low back pain and NP are truly major public health problems and represent a considerable socioeconomic burden (7-10). Unlike fatal diseases, such as cancer, diabetes, and cardiovascular conditions, NP is non-fatal, and while it does not affect years of life lost $(11,12)$, it significantly affects years lived with disability (YLD).

It is estimated that China's population is 1.407 billion (13), approximately one-fifth of the world population. Previous epidemiological studies on NP had small sample sizes and limited localities (14-16). The database of the GBD Study 2017 provides an updated and comprehensive assessment of the epidemiological characteristics of 354 diseases and injuries (17). The prevalence and YLD of NP in China are still unclear.

It was hypothesized that the prevalence and YLD for NP in China are diverse and would vary according to sex, age, and provinces/regions. Policy decision-makers also require age-, sex-, and province-specific information on the current status of and trend in prevalence and YLD for NP to allocate scarce health-care resources efficiently and precisely. Thus, we used the database of the GBD Study 2017 to estimate the age-, sex-, and province-specific point prevalence and YLD characteristics of NP in China. We present the following article in accordance with the MDAR reporting checklist (available at http://dx.doi.org/10.21037/ atm-20-6868).

\section{Methods}

The data examined in this study comprised Chinese data from the GBD Injuries and Risk Factors Study (2017). The GBD Study uses standardized metrics to critically appraise available information to update estimates and report diseases' burden (18). Briefly, the GBD Study (2017) provides comprehensive estimates of age, sex, location, and year for all major diseases and injuries for 195 countries and territories from 1990 to 2017 (17). Our present study focused on the prevalence and YLD of NP in 33 provinces/ regions in China, including 31 mainland provinces, municipalities, and autonomous regions and the Hong Kong and Macao Special Administrative Regions (no data from Taiwan were included).

NP was defined as NP with or without pain spreading into the upper limb(s) that lasts for at least one day $(4,19)$. The survey data, systematic reviews of published data, and gray literature sources were gathered, and Bayesian meta- regression by DisMod-MR 2.1 was used to synthesize the data to estimate the point prevalence and YLD outcomes of NP. Detailed descriptions of the modeling strategy of the estimation and validation have been published previously (17). The step-by-step estimation of the point prevalence and YLD of NP is summarized in Figure S1.

Disability weights (DWs) from the GBD Study (2017) (17) were used to represent the magnitude of health loss associated with NP. DWs were measured on a scale from 0 to 1 (in which " 0 " represents a state of full health and " 1 " represents a state equivalent to death) (20). The following four sequelae were developed to describe the different levels of NP severity and its associated functional loss $(17,20)$ :

(I) Mild NP (DW: 0.052; 95\% CI: 0.036-0.074): NP and difficulty turning the head and lifting things;

(II) Moderate NP (DW: 0.112; 95\% CI: 0.079-0.162): Constant NP and difficulty turning the head, holding arms up, and lifting things;

(III) Severe NP (DW: 0.226, 95\% CI: 0.147-0.323): Severe NP and difficulty turning the head and lifting things, headaches and arm pain, poor sleep, and feelings of tiredness and worry;

(IV) Most severe NP (DW: 0.300, 95\% CI: 0.199_ 0.434): Constant NP and arm pain, difficulty turning the head, holding arms up, and lifting things, headaches, poor sleep, and feelings of tiredness and worry. The study was conducted in accordance with the Declaration of Helsinki (as revised in 2013).

\section{Statistical analysis}

As NP does not cause mortality, the YLD and disabilityadjusted life years values were essentially the same. The unadjusted YLD of each sequela was calculated using the following formulas $(17,21)$ :

1) $\mathrm{YLD}_{\text {total }}=\mathrm{YLD}_{\text {sequela } 1}+\mathrm{YLD}_{\text {sequela2 } 2} \ldots+\mathrm{YLD}_{\text {sequela } a}$; and

2) $\mathrm{YLD}_{\text {sequela }}=$ Prevalence $_{\text {sequela }}$ * $D W_{\text {health state }}$

UIs were calculated using a propagating technique that has previously been described elsewhere $(17,22)$. Briefly, the UIs were calculated from all steps of data manipulations and stored in 1,000 draws; the final estimate was the mean estimate across all 1,000 draws, and the $95 \%$ UIs were the 25 th and 75 th ranked values across all 1,000 draws. Finally, to correct for comorbidity, a microsimulation was performed for each age, sex, location, and year and was used to calculate the comorbidity-adjusted YLD. 
Table 1 The changes of the age-standardized prevalence rate (per 100,000 persons) and all-age prevalent numbers (*1000s) of NP between 1990 and 2017 in China and Global

\begin{tabular}{|c|c|c|c|c|c|c|c|}
\hline & \multicolumn{3}{|c|}{1990} & \multicolumn{3}{|c|}{2017} & Changes \% \\
\hline \multicolumn{8}{|c|}{ Age-standardized prevalence rate ( $95 \%$ UI), per 100,000 persons } \\
\hline China & $4,532.6$ & $3,977.0$ & $5,113.9$ & $4,634.4$ & $4,078.6$ & $5,223.8$ & 2.2 \\
\hline Global & $3,582.7$ & $3,162.1$ & $4,032.6$ & $3,551.1$ & $3,139.5$ & $3,977.9$ & -0.9 \\
\hline China & 48,001 & 42,196 & 54,544 & 87,346 & 76,052 & 98,717 & 82.0 \\
\hline Global & 164,338 & 144,875 & 185,856 & 288,719 & 254,715 & 323,483 & 75.7 \\
\hline
\end{tabular}

NP, neck pain; LUI, lower uncertainty interval; UUI, upper uncertainty interval.

\section{Results}

\section{Prevalence}

We estimated that the NP's age-standardized point prevalence rate was $4,532.6$ per 100,000 persons in 1990 and increased slightly to $4,634.4$ per 100,000 persons in 2017 (Table 1). The estimated prevalence of NP was 48.0 million in 1990, dramatically increasing to 87.3 million in 2017 (an increase of 82.0\%) (Table 1 and Table S1).

A sex-specific analysis showed that females' agestandardized point prevalence rate was higher than that in males from 1990 to 2017. In 1990, the point prevalence was $5,267.5$ per 100,000 persons for females and 3,830.1 per 100,000 persons for males. In 2017, the point prevalence was $5,377.3$ per 100,000 persons for females and 3,898.8 per 100,000 persons for males.

For the age categories of $0-4$ years to $85-89$ years, the point prevalence of NP first increased and then decreased after approximately 70 to 74 years (Figure 1 ). We also found that the point prevalence in females increased faster than that in males. A comparison of the point prevalence rate of different age categories between 1990 and 2017 showed that the 15-19-year category had the highest increase (10.2\%), followed by the 10-14-year category (6.3\%) (Table S2).

In all 33 provinces/regions, Shanghai had the highest point prevalence rate of NP with 6,065.4 per 100,000 persons in 1990 and 5,740.3 per 100,000 persons in 2017. Hong Kong had the lowest point prevalence rate with 3631.1 per 100,000 persons in 1990 and 3,874.6 per 100,000 persons in 2017 (Figure 2 and Table S3). Sichuan had the highest NP prevalence in 1990 (4.7 million) but was replaced by Guangdong in 2017 (6.5 million). Due to the limited total population, Macao had the lowest
NP prevalence in 1990 and 2017 of 15,000 and 43,000, respectively (Figure 2 and Table S4).

\section{$Y L D$}

The age-standardized YLD rate of NP was 454.0 per 100,000 persons in 1990 . This rate increased slightly to 465.6 per 100,000 persons in 2017. The total age YLD of NP was 4.8 million in 1990, rising to 8.8 million in 2017 (an increase of $81.1 \%$ ) (Table 2 and Table S5). The sexspecific analysis also showed that the age-standardized YLD rate and all-age YLD for NP were higher in females than in males. The YLD first increased with age and then decreased (Figure 3). In 1990, the age category of peak YLD was approximately $35-54$ years, while in 2017, the age category of peak YLD was approximately 45-54 years, and reached 1.3 million for each age category of 45-49 and 50-54 years (Figure 3 and Tables S6,S7).

In all 33 provinces/regions, Shanghai had the highest age-standardized YLD rate of NP; that is, 606.6 per 100,000 persons in 1990 and 576.3 per 100,000 persons in 2017. Hong Kong had the lowest age-standardized YLD rate; that is, 366.6 per 100,000 persons in 1990 and 390.7 per 100,000 persons in 2017 (Figure 4 and Table S8). In 1990, 471000, Sichuan had the highest all-age YLD of NP. In 2017, at 649000, Guangdong had the highest all-age YLD of NP (Figure 4 and Table S9).

In 1990, NP was the third leading cause of YLD in China. In 2017, NP was the leading cause of YLD in China. For different provinces/regions, NP was ranked as the leading cause of YLD in 23/33 provinces/regions, the second leading cause in $8 / 33$, the third leading cause in $1 / 33$, and the fifth leading cause in $1 / 33$ (Table 3). 
A
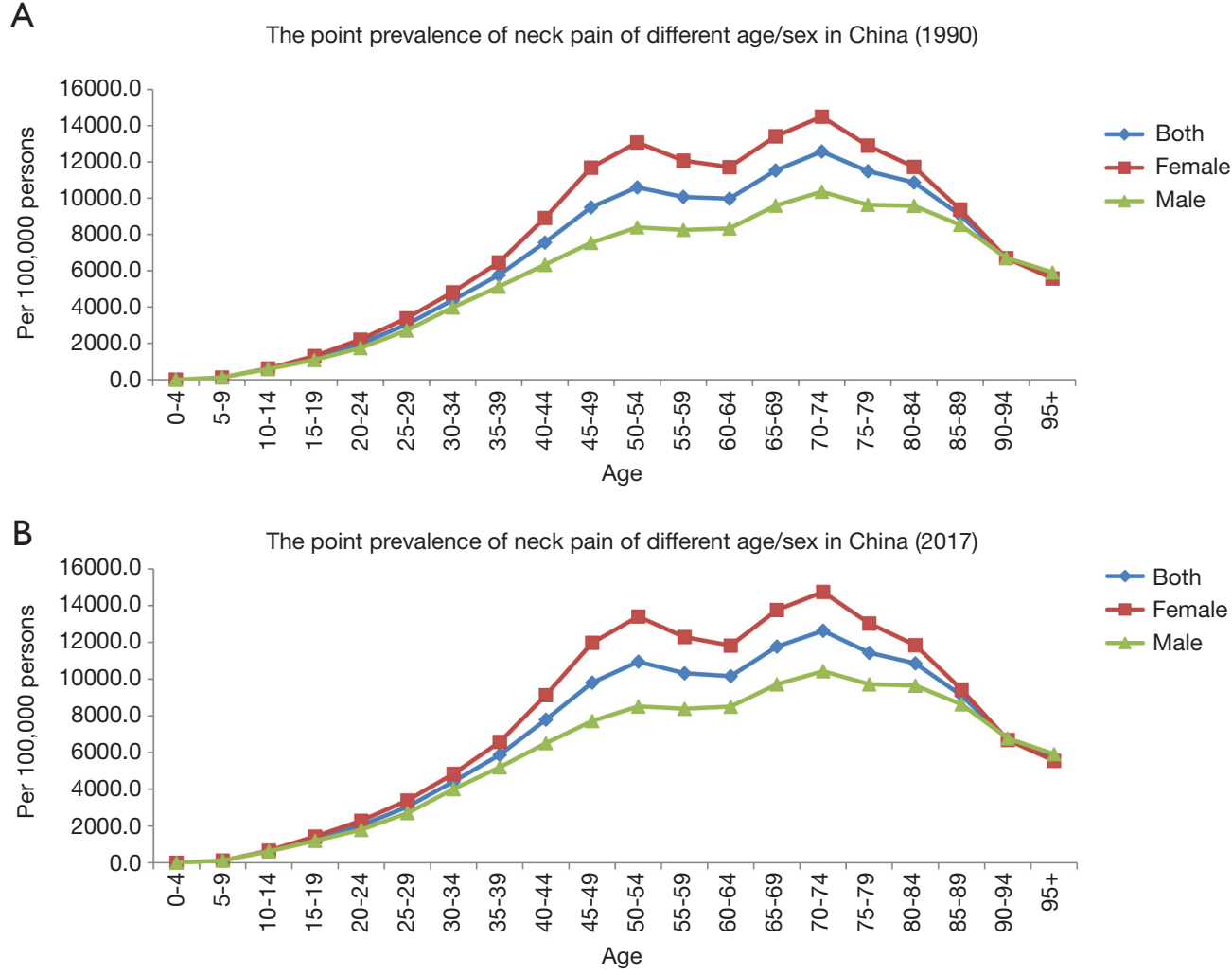

Figure 1 Age-specific analysis indicates that the point prevalence of NP increased with age in 1990 (A) and 2017 (B). The rise was faster in females than males, and decreased after adults reached $70-74$ years of age.

\section{Discussion}

This study was the first to undertake a systematic analysis of NP in China using GBD data. The major finding of the present study is that the prevalent numbers and YLD for NP have increased dramatically in China, and NP became the leading cause of YLD in China in 2017. Globally, NP was only ranked as the ninth cause of YLD in 2017 (17). In China, the age-standardized prevalence rate was 4,532.6 per 100,000 persons (in 1990) and 4,634.4 per 100,000 persons (in 2017). Notably, China's rates are higher than the global rates of 3,282.7 per 100,000 persons (in 1990) and 3,551.1 per 100,000 persons (in 2017). The age-standardized YLD rate in China was 454.0 per 100,000 persons (in 1990) and 465.6 per 100,000 persons (in 2017), which were higher than the global rates of 354.4 per 100,000 persons (in 1990) and 352.0 per 100,000 persons (in 2017). Thus, NP represents a serious problem in China and should receive more attention and be the subject of further research.

In the present study, we also found that Shanghai had the highest NP prevalence in both 1900 and 2017. Despite a $5.4 \%$ decrease in NP's point prevalence from 1990 to 2017, NP remained the leading cause of YLD in Shanghai. In most provinces/regions (27/33), the rank increased from 1990 to 2017 in China. The rank of NP causing YLD increased the most in Zhejiang and Gansu, and NP was ranked as the fifth leading cause of YLD in 1990 and as the leading cause in 2017 in the above two provinces.

Many risk factors predispose patients to the development of NP $(23,24)$. In the present study, we found that females were more likely to develop NP than males, which is consistent with previous studies' findings $(25,26)$. Other risk factors of NP include obesity, sleep problems, lifestyle, mood, distress, working in awkward/sustained postures, and poor general health (25-28); these risk factors are common in China currently $(29,30)$ and might be the reason for the increased NP in China. However, the major reason for the increased prevalent numbers and YLD can be attributed to the increase in China's population from 1990 to 2017. Fortunately, most of the risk factors are modifiable. Recently, various interventions have been shown to prevent 
A

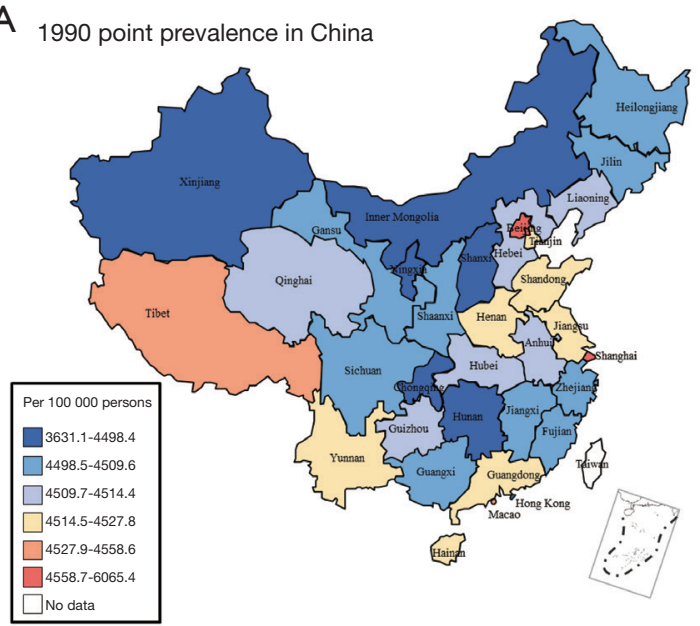

B 2017 point prevalence in China

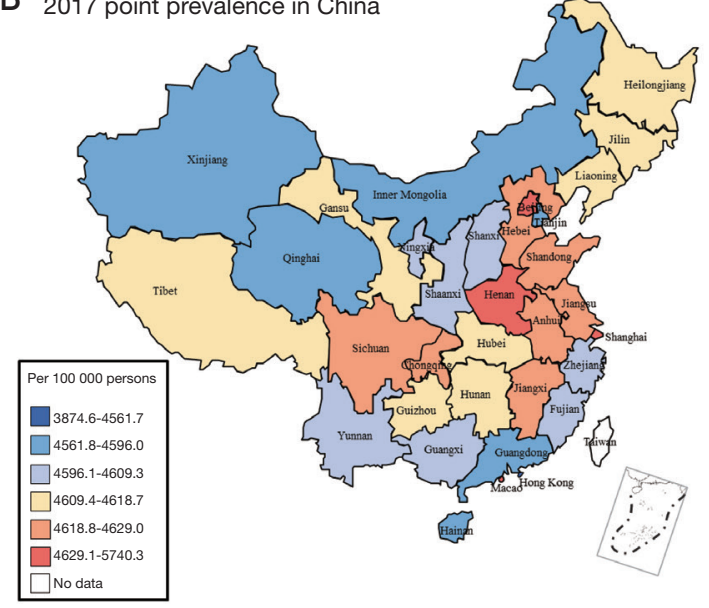

C Changes of point prevalence from 1990 to 2017

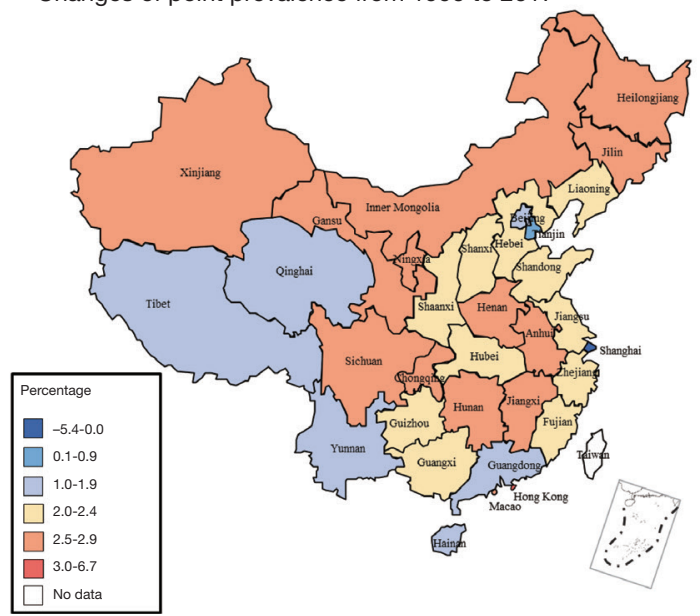

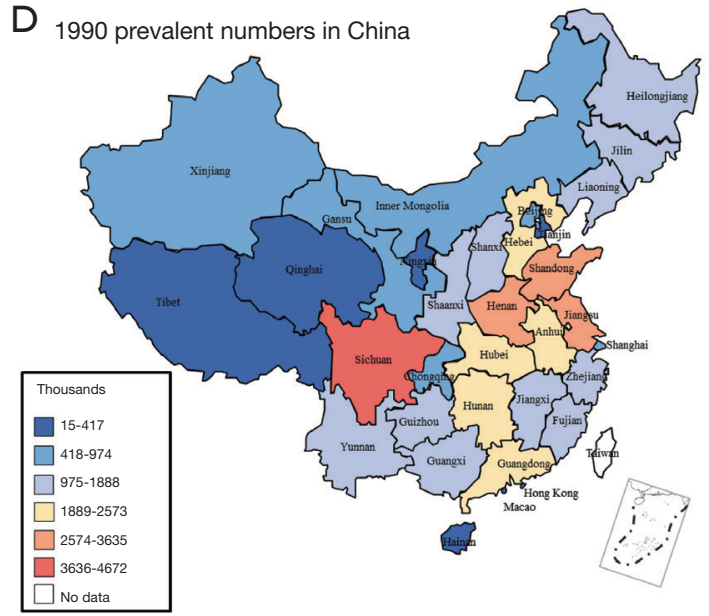

E 2017 prevalent numbers in China

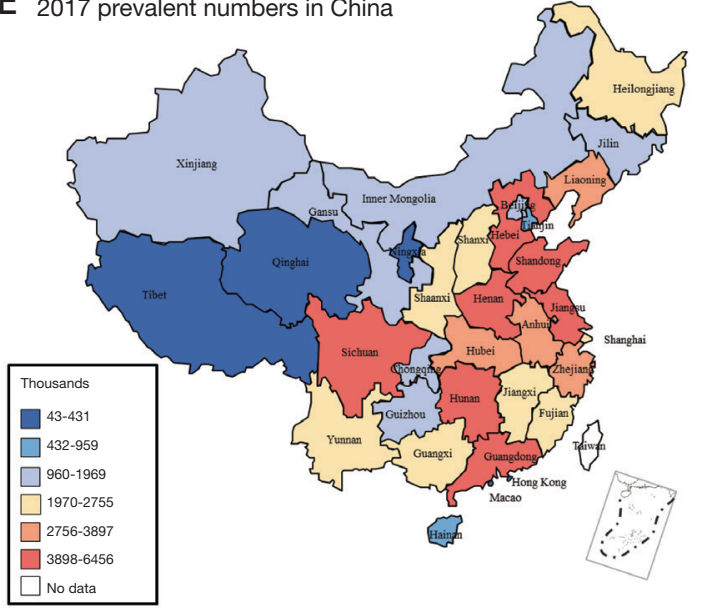

F Changes of prevalent numbers from 1990 to 2017

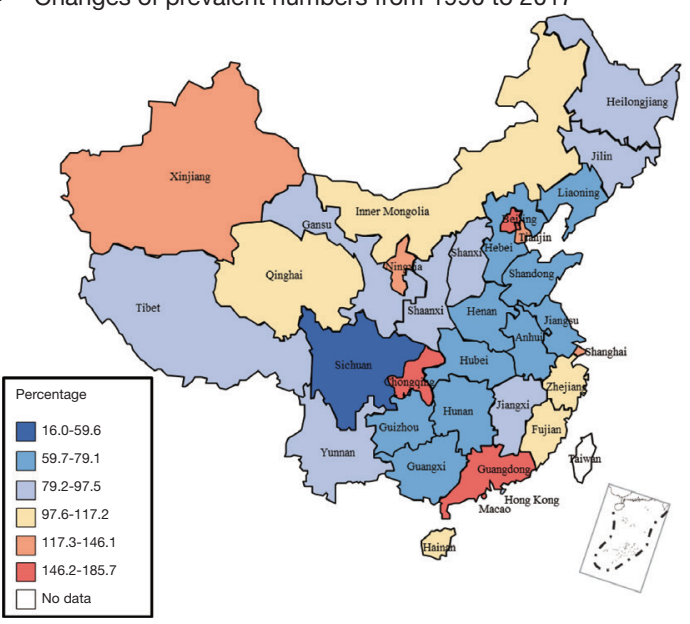

Figure 2 Map of age-standardized point prevalence and prevalent numbers of NP in China (No data of Taiwan) between 1990 and 2017. (A) The age-standardized point prevalence of neck pain in China at 1990; (B) the age-standardized point prevalence of neck pain in China at 2017; (C) the changes of age-standardized point prevalence of neck pain in China between 1990 and 2017; (D) the prevalent number of neck pain in China at 1990; (E) the prevalent number of neck pain in China at 2017; (F) the changes of prevalent number of neck pain in China between 1990 and 2017. 
Table 2 The changes of the age-standardized YLDs rate (per 100,000 persons) and all-age YLDs (*1000s) of NP between 1990 and 2017 in China

\begin{tabular}{|c|c|c|c|c|c|c|c|}
\hline & \multicolumn{3}{|c|}{1990} & \multicolumn{3}{|c|}{2017} & Changes \% \\
\hline \multicolumn{8}{|c|}{ Age-standardized YLDs rate (95\% UI), per 100,000 persons } \\
\hline China & 454.0 & 315.7 & 636.9 & 465.6 & 323.4 & 650.4 & 2.6 \\
\hline Global & 354.4 & 246.9 & 497.1 & 352.0 & 245.6 & 493.3 & -0.7 \\
\hline \multicolumn{8}{|c|}{ All-age YLDs (95\% UI), *1000s } \\
\hline China & 4,837 & 3,370 & 6,750 & 8,758 & 6,067 & 12,292 & 81.1 \\
\hline Global & 16,331 & 11,350 & 22,899 & 28,631 & 19,952 & 40,202 & 75.3 \\
\hline
\end{tabular}

YLDs, years lived with disability; NP, neck pain; LUI, lower uncertainty interval; UUI, upper uncertainty interval.
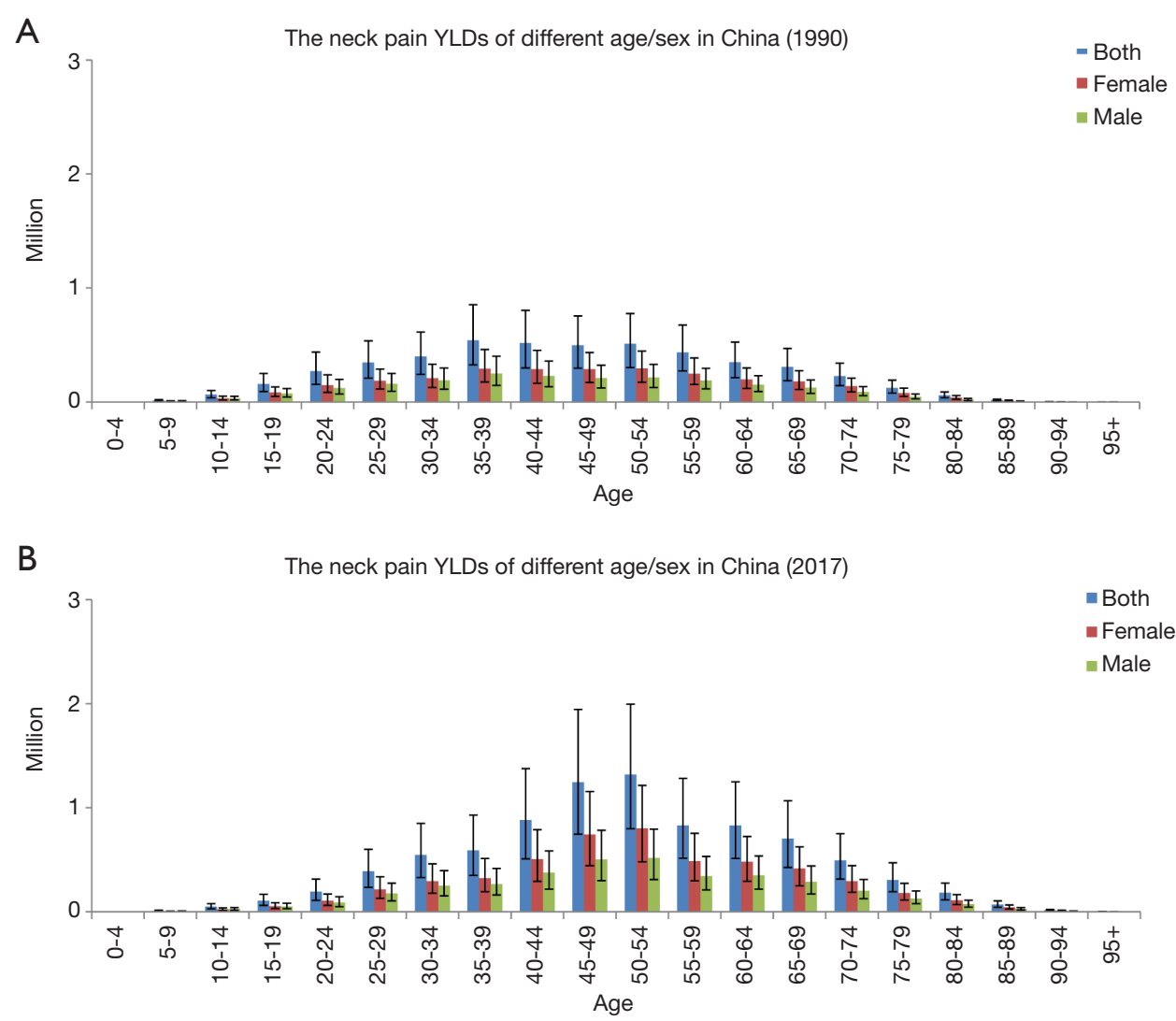

Figure 3 In both 1990 (A) and 2017 (B), the age-specific analysis shows that as age increased, the YLDs first increased and then decreased.

NP. A systematic review conducted by Linton and Van Tulder showed that exercise was an effective preventive intervention for NP (31). However, it has been shown that exercise therapy is not more cost-effective than other interventions for NP (32-34).

NP significantly affects sick leave and the workability of workers (35). Our study found that NP's point prevalence increased obviously after the age category of 20-24 (Figure 1). For YLD, those in the middle-aged population are the most greatly affected by NP, which is especially common among those aged 45-55 (Figure 3). Previous evidence has shown that workplace-based interventions for 
A 1990 YLDs rate in China

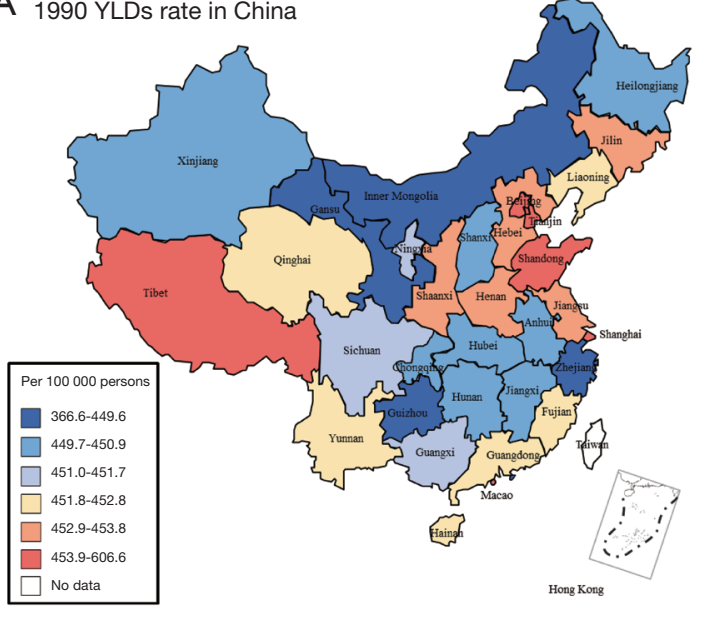

B 2017 YLDs rate in China

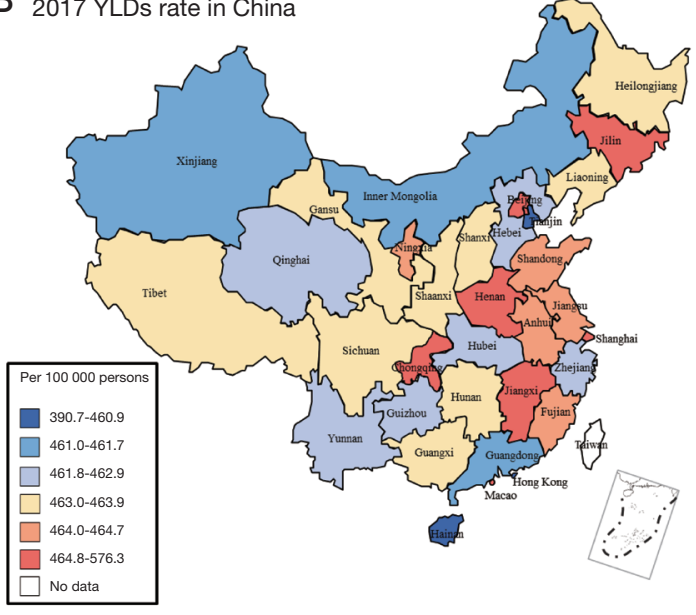

C Changes of YLDs rate from 1990 to 2017

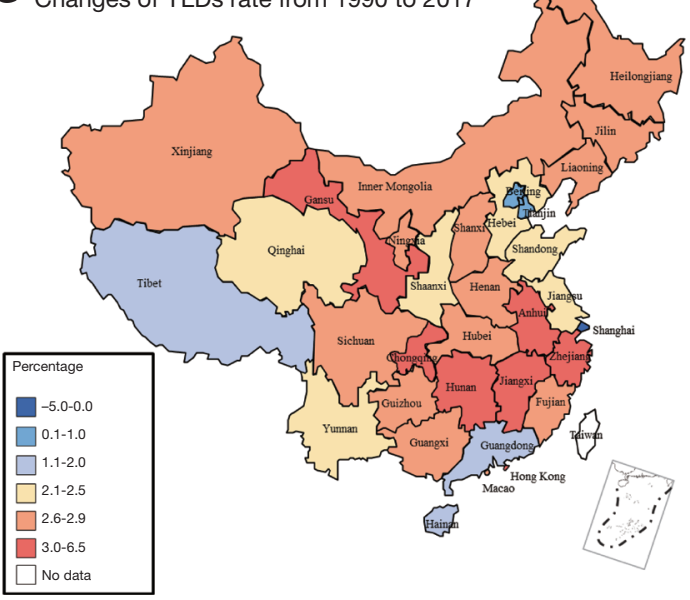

D 1990 YLDs in China

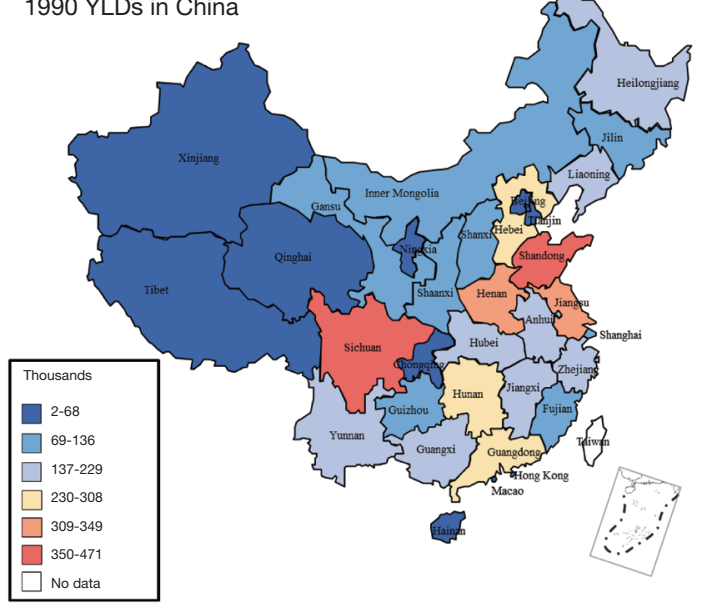

E 2017 YLDs in China

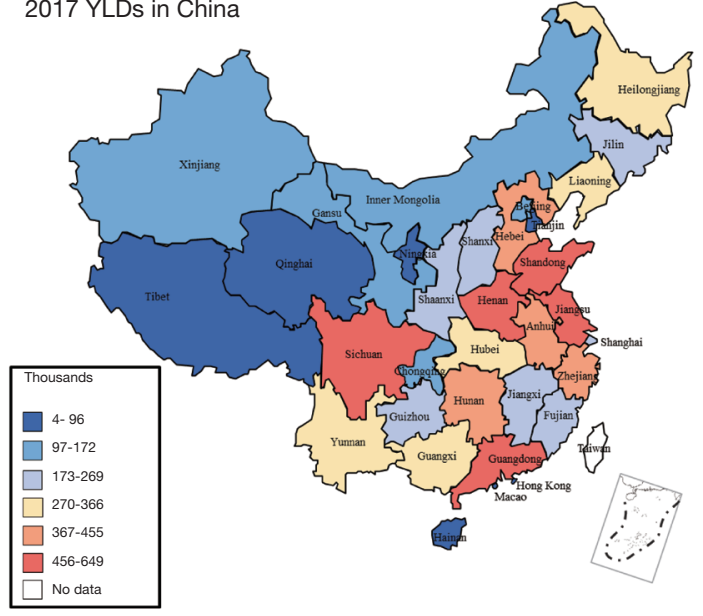

$\mathrm{F}$

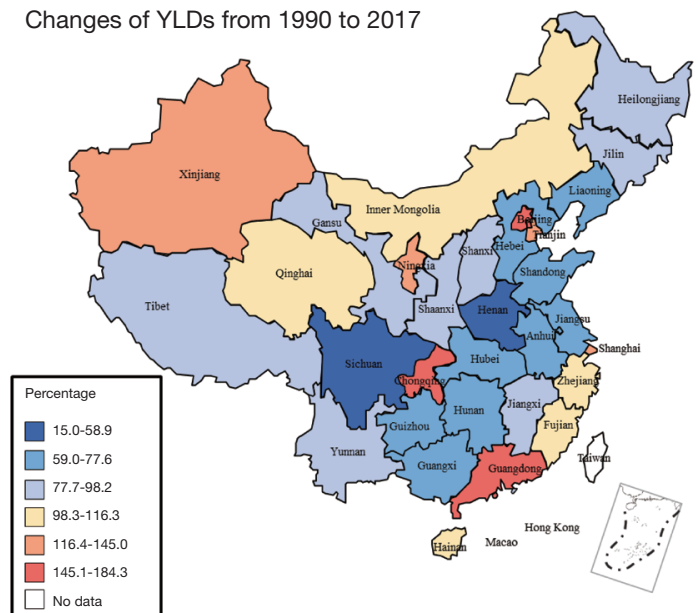

Figure 4 Map of age-standardized YLDs rate and all-age YLDs of NP in China (no data from Taiwan were included in the analyses between 1990 and 2017. (A) The age-standardized YLDs rate of neck pain in China at 1990; (B) the age-standardized YLDs rate of neck pain in China at 2017; (C) the changes of age-standardized YLDs rate of neck pain in China between 1990 and 2017; (D) the all-age YLDs of neck pain in China at 1990; (E) the all-age YLDs of neck pain in China at 2017; (F) the changes of all-age YLDs of neck pain in China between 1990 and 2017. 
Table 3 The percent of YLDs caused by NP in all diseases by provinces/regions (in 1990 and 2017)

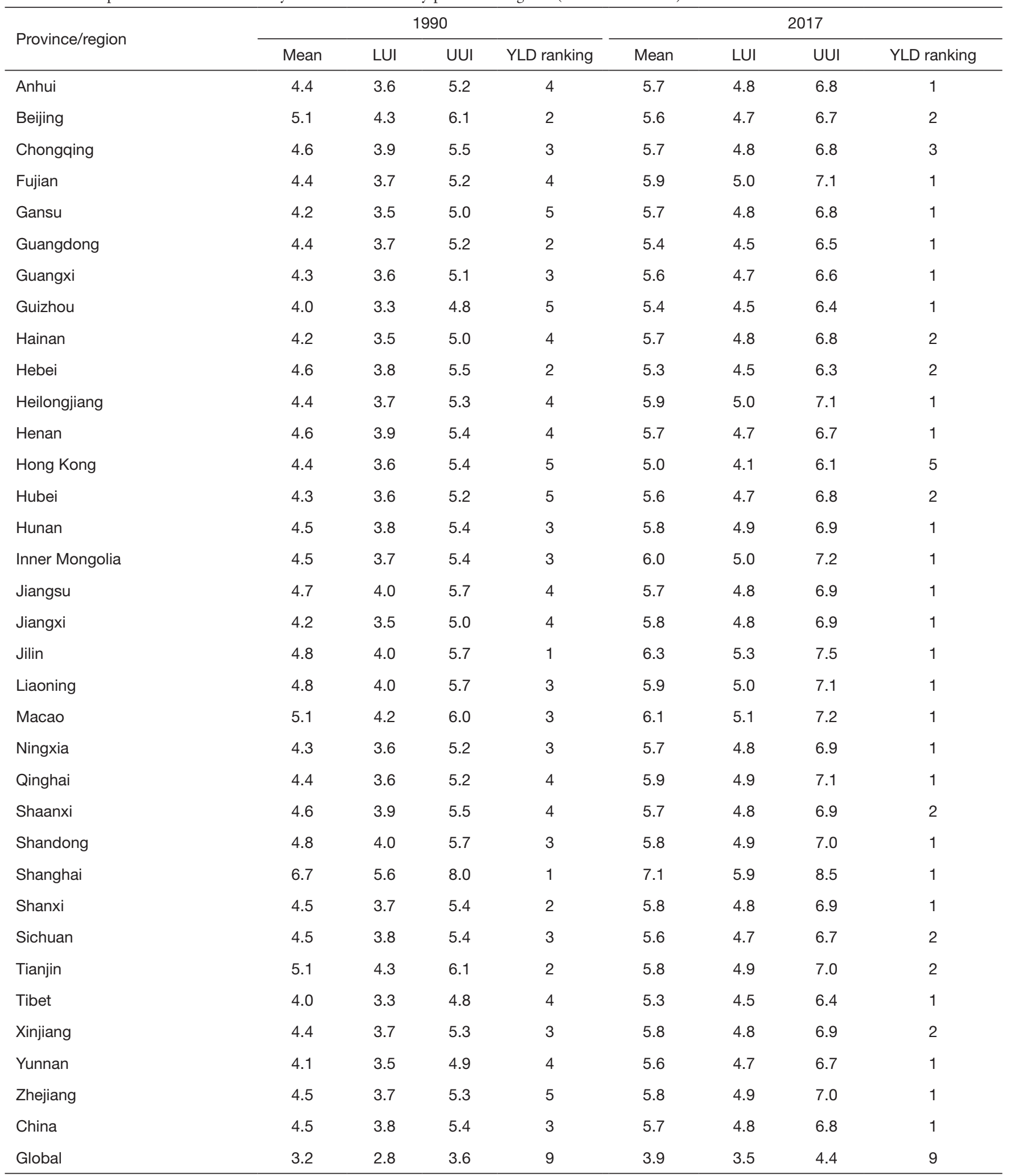

The LUI and UUI are the 2.5 to 97.5 centile values of the $95 \%$ Uls. The rank of all-age YLDs caused by NP in all diseases included by GBD study 2017. YLDs, years lived with disability; NP, neck pain; LUI, lower uncertainty interval; UUI, upper uncertainty interval. 
office workers can reduce NP (36) and might be effective for workers.

\section{Policy implications}

In recent years, governments and funders have paid considerable attention to fatal chronic diseases, such as cardiovascular diseases, cancer, respiratory diseases, and diabetes (37-39). However, despite being a serious public burden, non-fatal chronic diseases (such as NP and back pain) that induce disabilities and are associated with sick leave among workers $(35,40)$ are inadequately recognized.

In the past 28 years, the increasing NP problem, which has become the leading cause of YLD in China, has created significant health-care challenges. We recommend that governments, policymakers, and society generally pay more attention to NP, and the NP should be better recognized and resourced.

\section{Strengths and limitations}

The present study provides the most comprehensive prevalence and YLD estimates of NP in China at both the national and provincial/regional level. The GBD Study (2017) uses the updated DisMod-MR tool 2.1, constructions of the sociodemographic index adjusted by comorbidity, to improve the results' accuracy. However, this study also had some limitations. First, some health information reported by the national authorities is time-lagged. Second, all of the results were estimated and reliant on models rather than original data. Third, the DWs were based on data from selected countries (i.e., Bangladesh, Indonesia, Peru, Tanzania, the USA, Hungary, Italy, the Netherlands, and Sweden) before 2013, and a global web-based survey (20). Further surveys in more countries would improve the generalizability of the DWs. Fourth, the present study did not include urban- or rural-stratified results.

\section{Conclusions}

Overall, the age-standardized point prevalence rate and YLD of NP slightly increased from 1990 to 2017, while the prevalence rate and total YLD of NP increased dramatically in China. NP was the leading cause of disability burden in China in 2017; however, it is currently inadequately recognized and should receive more attention from governments and policymakers.

\section{Acknowledgments}

Funding: WL was supported by the National Key Research and Development Plan of China (2018YFC1315304). AM was supported by the National Natural Science Foundation of China (81501933), Wenzhou leading talent innovative project (RX2016004), Wenzhou Municipal Science and Technology Bureau (Y20190018), and Zhejiang Provincial Medical Technology Foundation of China (2018KY129).

\section{Footnote}

Reporting Checklist: The authors have completed the MDAR reporting checklist. Available at http://dx.doi.org/10.21037/ atm-20-6868

Conflicts of Interest: All authors have completed the ICMJE uniform disclosure form (available at http://dx.doi. org/10.21037/atm-20-6868). The authors have no conflicts of interest to declare.

Ethical Statement: The authors are accountable for all aspects of the work in ensuring that questions related to the accuracy or integrity of any part of the work are appropriately investigated and resolved. The study was conducted in accordance with the Declaration of Helsinki (as revised in 2013).

Open Access Statement: This is an Open Access article distributed in accordance with the Creative Commons Attribution-NonCommercial-NoDerivs 4.0 International License (CC BY-NC-ND 4.0), which permits the noncommercial replication and distribution of the article with the strict proviso that no changes or edits are made and the original work is properly cited (including links to both the formal publication through the relevant DOI and the license). See: https://creativecommons.org/licenses/by-nc-nd/4.0/.

\section{References}

1. Fejer R, Kyvik KO, Hartvigsen J. The prevalence of neck pain in the world population: a systematic critical review of the literature. Eur Spine J 2006;15:834-48.

2. Hoy DG, Protani M, De R, et al. The epidemiology of neck pain. Best Pract Res Clin Rheumatol 2010;24:783-92.

3. Jiménez-Trujillo I, López-de-Andrés A, Del Barrio JL, et al. Gender Differences in the Prevalence and Characteristics of Pain in Spain: Report from a 
Population-Based Study. Pain Med 2019;20:2349-59.

4. Hoy D, March L, Woolf A, et al. The global burden of neck pain: estimates from the global burden of disease 2010 study. Ann Rheum Dis 2014;73:1309-15.

5. Dieleman JL, Baral R, Birger M, et al. US Spending on Personal Health Care and Public Health, 1996-2013. JAMA 2016;316:2627-46.

6. Williams A, Kamper SJ, Wiggers JH, et al. Musculoskeletal conditions may increase the risk of chronic disease: a systematic review and meta-analysis of cohort studies. BMC Med 2018;16:167.

7. Herman PM, Luoto JE, Kommareddi M, et al. Patient Willingness to Pay for Reductions in Chronic Low Back Pain and Chronic Neck Pain. J Pain 2019;20:1317-27.

8. Cohen SP, Hooten WM. Advances in the diagnosis and management of neck pain. BMJ 2017;358:j3221.

9. Raciborski F, Gasik R, Klak A. Disorders of the spine. A major health and social problem. Reumatologia 2016;54:196-200.

10. Wu A, March L, Zheng X, et al. Global low back pain prevalence and years lived with disability from 1990 to 2017: estimates from the Global Burden of Disease Study 2017. Ann Transl Med 2020;8:299.

11. Lee H, Hubscher M, Moseley GL, et al. How does pain lead to disability? A systematic review and meta-analysis of mediation studies in people with back and neck pain. Pain 2015;156:988-97.

12. Muscari A, Bianchi G, Forti P, et al. Inverse Association Between Neck Pain and All-Cause Mortality in Community-Dwelling Older Adults. Pain Med 2018;19:2377-86.

13. Countrymeters. Accessed by Oct 30th, 2019. Available online: http://countrymeters.info/ct/China

14. Zeng SY, Gong Y, Zhang YP, et al. Changes in the Prevalence of Rheumatic Diseases in Shantou, China, in the Past Three Decades: A COPCORD Study. PLoS One 2015;10:e0138492.

15. Jackson T, Chen H, Iezzi T, et al. Prevalence and correlates of chronic pain in a random population study of adults in Chongqing, China. Clin J Pain 2014;30:346-52.

16. Yue P, Liu F, Li L. Neck/shoulder pain and low back pain among school teachers in China, prevalence and risk factors. BMC Public Health 2012;12:789.

17. GBD 2017 Disease and Injury Incidence and Prevalence Collaborators. Global, regional, and national incidence, prevalence, and years lived with disability for 354 diseases and injuries for 195 countries and territories, 1990-2017: a systematic analysis for the Global Burden of Disease Study
2017. Lancet 2018;392:1789-858. Erratum in: Lancet 2019;393:e44.

18. Murray CJ, Lopez AD. Measuring the global burden of disease. N Engl J Med 2013;369:448-57.

19. Guzman J, Hurwitz EL, Carroll LJ, et al. A new conceptual model of neck pain: linking onset, course, and care: the Bone and Joint Decade 2000-2010 Task Force on Neck Pain and Its Associated Disorders. Spine (Phila Pa 1976) 2008;33:S14-23.

20. Salomon JA, Haagsma JA, Davis A, et al. Disability weights for the Global Burden of Disease 2013 study. Lancet Glob Health 2015;3:e712-23.

21. Wu A, Dong W, Liu S, et al. The prevalence and years lived with disability caused by low back pain in China, 1990 to 2016: findings from the global burden of disease study 2016. Pain 2019;160:237-45.

22. GBD 2017 Causes of Death Collaborators. Global, regional, and national age-sex-specific mortality for 282 causes of death in 195 countries and territories, 1980-2017: a systematic analysis for the Global Burden of Disease Study 2017. Lancet 2018;392:1736-88. Erratum in: Lancet 2019;393:e44. Erratum in: Lancet 2018;392:2170.

23. Chinese Center for Disease Control and Prevention. Report on Chronic Disease Risk Factor Surveillance in China, 2010. Beijing, China: Military Medical Science Press, 2012.

24. Linton SJ. A review of psychological risk factors in back and neck pain. Spine (Phila Pa 1976) 2000;25:1148-56.

25. Croft PR, Lewis M, Papageorgiou AC, et al. Risk factors for neck pain: a longitudinal study in the general population. Pain 2001;93:317-25.

26. Kääriä S, Laaksonen $M$, Rahkonen $O$, et al. Risk factors of chronic neck pain: a prospective study among middle-aged employees. Eur J Pain 2012;16:911-20.

27. Kim R, Wiest C, Clark K, et al. Identifying risk factors for first-episode neck pain: A systematic review. Musculoskelet Sci Pract 2018;33:77-83.

28. Ben Ayed H, Yaich S, Trigui M, et al. Prevalence, Risk Factors and Outcomes of Neck, Shoulders and Low-Back Pain in Secondary-School Children. J Res Health Sci 2019;19:e00440.

29. Ying-Xiu Z, Shu-Rong W. Secular trends in body mass index and the prevalence of overweight and obesity among children and adolescents in Shandong, China, from 1985 to 2010. J Public Health (Oxf) 2012;34:131-7.

30. Yeung SS, Genaidy A, Deddens J, et al. Prevalence of musculoskeletal symptoms in single and multiple body regions and effects of perceived risk of injury 
among manual handling workers. Spine (Phila $\mathrm{Pa} 1976)$ 2002;27:2166-72.

31. Linton SJ, van Tulder MW. Preventive interventions for back and neck pain problems: what is the evidence? Spine (Phila Pa 1976) 2001;26:778-87.

32. Miyamoto GC, Lin CC, Cabral CMN, et al. Costeffectiveness of exercise therapy in the treatment of nonspecific neck pain and low back pain: a systematic review with meta-analysis. Br J Sports Med 2019;53:172-81.

33. Lauche R, Stumpe C, Fehr J, et al. The Effects of Tai Chi and Neck Exercises in the Treatment of Chronic Nonspecific Neck Pain: A Randomized Controlled Trial. J Pain 2016;17:1013-27.

34. Hagen KB, Dagfinrud H, Moe RH, et al. Exercise therapy for bone and muscle health: an overview of systematic reviews. BMC Med 2012;10:167.

35. Hallman DM, Holtermann A, Dencker-Larsen S, et al. Are trajectories of neck-shoulder pain associated with sick leave and work ability in workers? A 1-year prospective study. BMJ Open 2019;9:e022006.

36. Chen X, Coombes BK, Sjogaard G, et al. Workplace-Based

Cite this article as: $\mathrm{Wu} \mathrm{A}$, Dong $\mathrm{W}$, Zeng $\mathrm{X}, \mathrm{Xu} \mathrm{X}, \mathrm{Xu} \mathrm{T}$, Zhang K, Tian H, Zhao J, Wang X, Zhou M. Neck pain is the leading cause of disability burden in China: findings from the Global Burden of Disease Study 2017. Ann Transl Med 2021;9(9):777. doi: 10.21037/atm-20-6868
Interventions for Neck Pain in Office Workers: Systematic Review and Meta-Analysis. Phys Ther 2018;98:40-62.

37. Zhou M, Wang H, Zhu J, et al. Cause-specific mortality for 240 causes in China during 1990-2013: a systematic subnational analysis for the Global Burden of Disease Study 2013. Lancet 2016;387:251-72.

38. United Nations. Goal 3: Ensure healthy lives and promote well-being for all at all ages. Accessed by Oct 30th, 2019. Available online: https://www.un.org/ sustainabledevelopment/health/.

39. The State Council of the People's Republic of China. State Council issues plan to prevent chronic diseases. Accessed by Oct 30th, 2019. Available online: http:// english.gov.cn/policies/latest_releases/2017/02/14/ content_281475567482818.htm

40. Trompeter K, Fett D, Platen P. Prevalence of Back Pain in Sports: A Systematic Review of the Literature. Sports Med 2017;47:1183-207.

(English Language Editors: L. Huleatt and J. Chapnick) 


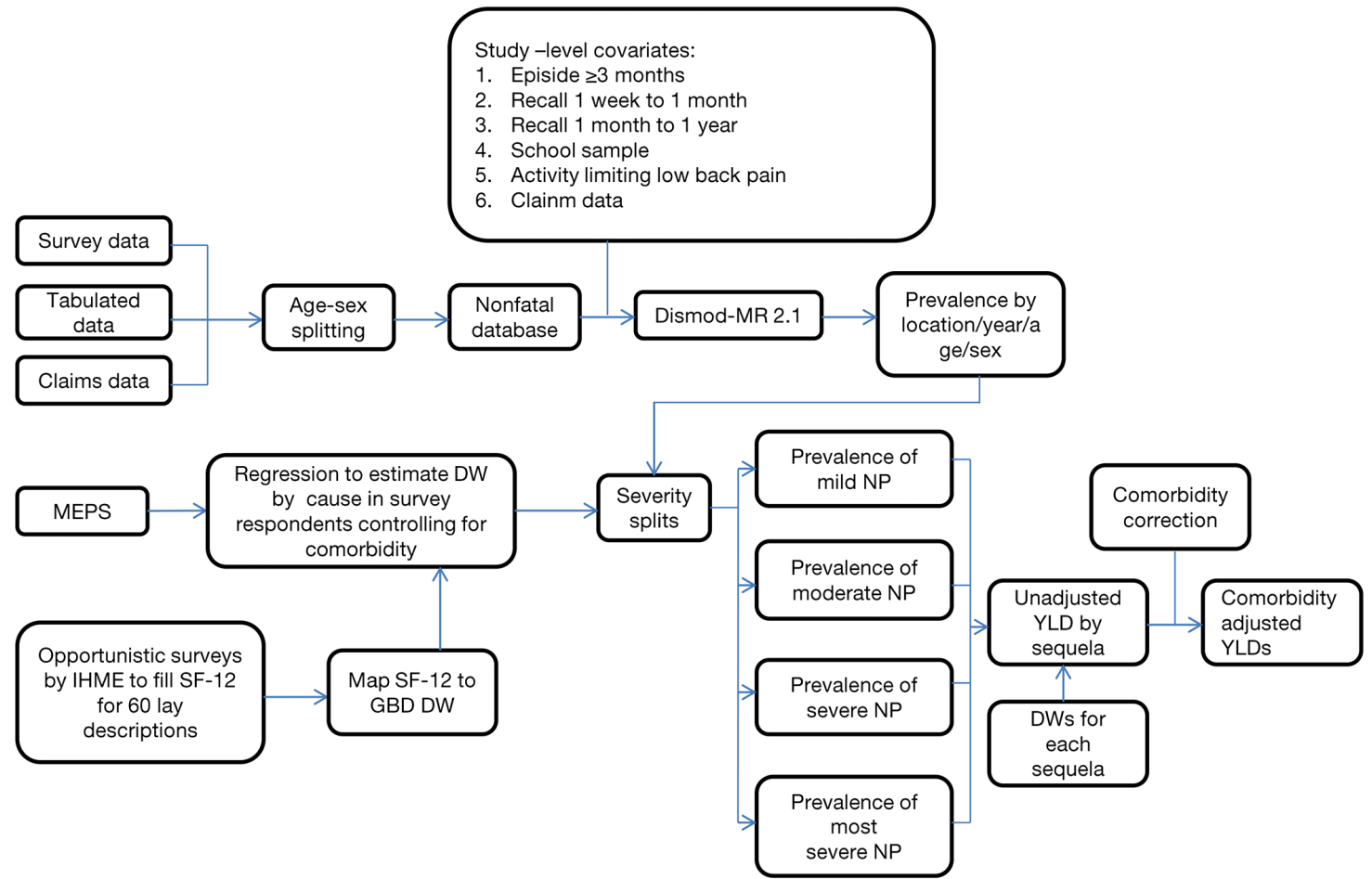

Figure S1 Steps taken in estimating the global burden of neck pain, GBD study 2017. 
Table S1 The detailed information of prevalence age-standardized prevalence rate and all-age prevalence number of neck pain in China from 1990 to 2017

\begin{tabular}{|c|c|c|c|c|c|c|}
\hline & \multicolumn{3}{|c|}{ All-Age prevalence number (95\% UI), *1000s } & \multicolumn{3}{|c|}{ Age-Standardized prevalence rate $(95 \%$ UI), per 100,000 persons } \\
\hline \multicolumn{7}{|l|}{1990} \\
\hline Female & 27168 & 23759 & 30827 & 5267.5 & 4609.6 & 5961.9 \\
\hline Male & 20833 & 18232 & 23747 & 3830.1 & 3362.1 & 4333.6 \\
\hline \multicolumn{7}{|l|}{1995} \\
\hline Female & 30834 & 26954 & 34934 & 5267.4 & 4609.7 & 5961.5 \\
\hline Male & 23573 & 20668 & 26808 & 3830.4 & 3362.1 & 4333.7 \\
\hline Both & 54407 & 47718 & 61627 & 4532.8 & 3977.1 & 5113.9 \\
\hline Male & 26888 & 23606 & 30932 & 3885.6 & 3430.3 & 4416.6 \\
\hline Both & 62690 & 55410 & 71177 & 4622.7 & 4072.0 & 5223.8 \\
\hline \multicolumn{7}{|l|}{2005} \\
\hline Female & 42192 & 36675 & 48335 & 5614.7 & 4901.2 & 6392.8 \\
\hline Male & 29836 & 26219 & 34204 & 3887.3 & 3431.6 & 4417.9 \\
\hline Both & 72028 & 63027 & 81910 & 4738.1 & 4165.1 & 5358.5 \\
\hline \multicolumn{7}{|l|}{2010} \\
\hline Female & 46148 & 40024 & 52940 & 5517.3 & 4817.9 & 6269.9 \\
\hline Both & 85145 & 74079 & 96608 & 4653.4 & 4100.7 & 5242.1 \\
\hline \multicolumn{7}{|l|}{2017} \\
\hline Female & 50940 & 44146 & 58032 & 5377.3 & 4688.5 & 6097.4 \\
\hline Male & 36407 & 31847 & 41352 & 3898.8 & 3431.4 & 4405.9 \\
\hline Both & 87346 & 76052 & 98717 & 4634.4 & 4078.6 & 5223.8 \\
\hline
\end{tabular}

LUI, lower uncertainty interval; UUI, upper uncertainty interval. 
Table S2 The detailed information of the point prevalence rate of different age categories between 1990 and 2017

1990 prevalence rate $(95 \%$ UII), per 100,000 2017 prevalence rate (95\% UI), per 100,000

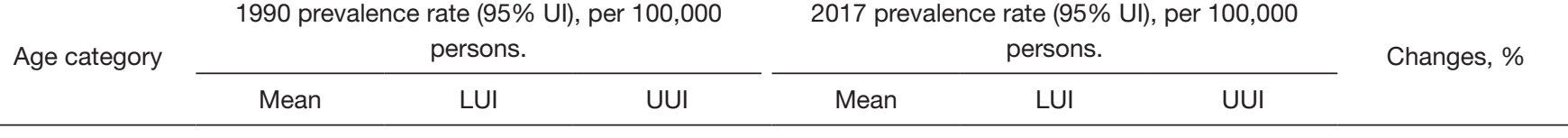

$0-4$

$\begin{array}{llllllll}\text { Female } & 0.0 & 0.0 & 0.0 & 0.0 & 0.0 & 0.0 & 0.00 \\ \text { Male } & 0.0 & 0.0 & 0.0 & 0.0 & 0.0 & 0.0 & 0.00 \\ \text { Both } & 0.0 & 0.0 & 0.0 & 0.0 & 0.0 & 0.0 & 0.00\end{array}$

5-9

\begin{tabular}{llllllll} 
Female & 115.2 & 68.4 & 172.8 & 116.9 & 69.9 & 189.5 & 1.48 \\
\hline & 118.2 & 69.3 & 1840 & 118.4 & 68.3 & 187.7 & 0.17
\end{tabular}

$\begin{array}{llllllll}\text { Male } & 118.2 & 69.3 & 184.0 & 118.4 & 68.3 & 187.7 & 0.17\end{array}$

$\begin{array}{llllllll}\text { Both } & 116.8 & 69.3 & 178.2 & 117.7 & 69.5 & 188.5 & 0.77\end{array}$

$10-14$

$\begin{array}{llllllll}\text { Female } & 613.3 & 429.7 & 841.9 & 657.4 & 469.3 & 910.4 & 7.19 \\ \text { Male } & 581.8 & 405.4 & 802.3 & 615.9 & 433.6 & 848.8 & 5.86\end{array}$

$\begin{array}{llllllll}\text { Both } & 597.1 & 418.9 & 820.2 & 634.9 & 455.4 & 876.6 & 6.33\end{array}$

$\begin{array}{llllllll}15-19 & & & & & & & \\ \text { Female } & 1293.9 & 866.7 & 1832.3 & 1429.9 & 970.2 & 2052.5 & 10.51\end{array}$

$\begin{array}{llllllll}\text { Male } & 1081.7 & 722.2 & 1548.7 & 1196.2 & 806.3 & 1682.8 & 10.59\end{array}$

$\begin{array}{llllllll}\text { Both } & 1184.9 & 785.0 & 1690.5 & 1305.6 & 889.4 & 1851.2 & 10.19\end{array}$

$\begin{array}{llllllll}20-24 & & & & & & & \\ \text { Female } & 2208.7 & 1486.4 & 3128.3 & 2284.7 & 1524.6 & 3245.4 & 3.44\end{array}$

\begin{tabular}{llllllll} 
Female & 2208.7 & 1486.4 & 3128.3 & 2284.7 & 1524.6 & 3245.4 & 3.44 \\
Male & 1739.3 & 1179.0 & 2491.2 & 1791.4 & 1202.8 & 2564.0 & 3.00 \\
\hline & 1968.7 & 1397.8 & 2786.0 & 2029.4 & 1368.2 & 259.4 & 3.08
\end{tabular}

$\begin{array}{llllllll}\text { Both } & 1968.7 & 1337.8 & 2786.0 & 2029.4 & 1368.2 & 2859.4 & 3.08\end{array}$

$\begin{array}{llllllll}25-29 & & & & & & & \\ \text { Female } & 3376.6 & 2422.4 & 4719.3 & 3391.9 & 2416.9 & 4791.7 & 0.45\end{array}$

$\begin{array}{llllllll}\text { Male } & 2713.7 & 1931.0 & 3826.0 & 2705.6 & 1928.0 & 3677.7 & -0.30\end{array}$

$\begin{array}{llllllll}\text { Both } & 3036.1 & 2170.3 & 4182.3 & 3045.8 & 2184.6 & 4250.8 & 0.32\end{array}$

$\begin{array}{crrrrrrr}30-34 \\ \text { Female } & 4812.9 & 3522.6 & 6636.4 & 4841.1 & 3495.7 & 6681.7 & 0.59\end{array}$

$\begin{array}{llllllll}\text { Male } & 3978.2 & 2881.1 & 5533.6 & 4011.8 & 2948.3 & 5569.7 & 0.84\end{array}$

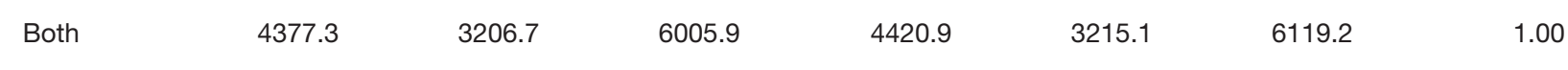

$\begin{array}{llllllll}35-39 & & & & & & & \\ \text { Female } & 6456.7 & 4673.8 & 8907.3 & 6576.6 & 4682.2 & 9238.4 & 1.86\end{array}$

$\begin{array}{llllllll}\text { Male } & 5121.5 & 3668.7 & 7117.7 & 5196.7 & 3740.9 & 7334.7 & 1.47\end{array}$

$\begin{array}{llllllll}\text { Both } & 5766.1 & 4203.9 & 7911.0 & 5874.1 & 4161.7 & 8263.9 & 1.87\end{array}$

$\begin{array}{llllllll}\text { 40-44 } & & & & & & & \\ \text { Female } & 8908.8 & 5788.8 & 12398.4 & 9127.4 & 6012.2 & 12872.4 & 2.45\end{array}$

$\begin{array}{lrrrrrr}\text { Both } & 7556.1 & 5003.1 & 10427.5 & 7793.3 & 5080.0 & 10775.2\end{array}$

45-49

$\begin{array}{lccccccc}\text { Female } & 11688.3 & 8248.8 & 15723.1 & 11973.1 & 8513.8 & 16463.2 & 2.44 \\ \text { Male } & 7542.6 & 5305.9 & 10386.1 & 7716.3 & 5524.3 & 10659.0 & 2.30\end{array}$

$\begin{array}{llllllll}\text { Both } & 9500.6 & 6775.0 & 12828.6 & 9805.8 & 7013.4 & 13437.0 & 3.21\end{array}$

\begin{tabular}{llllllll} 
50-54 & & & & & & & \\
Female & 13077.7 & 9292.2 & 17531.7 & 13404.7 & 9476.1 & 17904.9 & 2.50 \\
\hline & 8395.6 & 583.5 & 11464.7 & 8510.3 & 595.8 & 11427.0 & 1.37
\end{tabular}

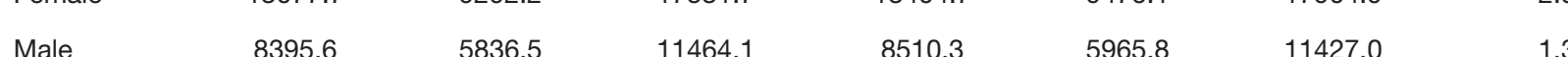

$\begin{array}{llllllll}\text { Both } & 10599.1 & 7525.1 & 14111.9 & 10947.4 & 7750.3 & 14577.7 & 3.29\end{array}$

$\begin{array}{lrrrrrrr}55-59 & & & & & & & \\ \text { Female } & 12073.8 & 8339.1 & 16931.5 & 12289.2 & 8502.7 & 17304.3 & 1.78\end{array}$

$\begin{array}{llllllll}\text { Male } & 8255.7 & 5555.0 & 11795.9 & 8383.5 & 5782.7 & 12140.3 & 1.55\end{array}$

$\begin{array}{llllllll}\text { Both } & 10072.6 & 6937.4 & 14077.6 & 10315.8 & 7170.5 & 14455.6\end{array}$

$\begin{array}{crrrrrrr}60-64 & & & & & & & \\ \text { Female } & 11719.6 & 8191.6 & 15826.2 & 11827.1 & 8399.0 & 15887.7 & 0.92\end{array}$

Male - $8334.5-5832.4-11173.1-8498.1-6026.4-11480.2$

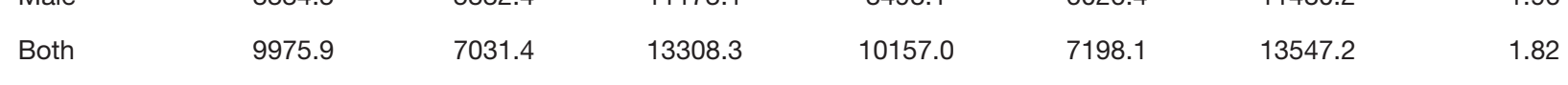

\begin{tabular}{llllllll} 
Female & 13416.7 & 9465.0 & 18058.9 & 13761.7 & 9753.9 & 18331.7 & 2.57 \\
\hline & 9589.9 & 6505 & 13015.7 & 97130 & 6904.9 & 1339.5 & 1.28
\end{tabular}

$\begin{array}{lllllll}\text { Male } \quad 9589.9 & 6550.5 & 13015.7 & 9713.0 & 6904.9 & 133390.5 & 1.28\end{array}$

$\begin{array}{llrrrrrr}\text { Both } & 11534.2 & 8136.0 & 15456.9 & 11768.0 & 8362.8 & 15862.1 & 2.03\end{array}$

$\begin{array}{cccccccc}70-74 & & & & & & & \\ \text { Female } & 14499.3 & 10399.5 & 19729.0 & 14749.5 & 10533.2 & 20009.0 & 1.73\end{array}$

$\begin{array}{llllllll}\text { Male } & 10358.7 & 7099.3 & 14426.4 & 10430.4 & 7204.5 & 14461.4 & 0.69\end{array}$

$\begin{array}{llllllll}\text { Both } & 12578.8 & 9198.4 & 17108.3 & 12635.9 & 9015.2 & 17129.8 & 0.45\end{array}$

$\begin{array}{llllllll}75-79 & & & & & & & \\ \text { Female } & 12903.0 & 9175.0 & 17657.3 & 13026.5 & 9200.2 & 17948.6 & 0.96\end{array}$

\begin{tabular}{llllllll} 
Male & 9636.2 & 6744.5 & 17657.3 & 13026.5 & 9200.2 & 17948.6 & 0.96 \\
\hline
\end{tabular}

$\begin{array}{llllllll}\text { Both } & 11494.9 & 8211.0 & 15945.8 & 11432.5 & 8123.3 & 15822.7 & -0.54\end{array}$

$\begin{array}{llllllll}80-84 & & & & & & & \\ \text { Female } & 11728.4 & 8260.8 & 16198.8 & 11848.9 & 8273.5 & 16494.5 & 1.03\end{array}$

$\begin{array}{llllllll}\text { Male } & 9580.9 & 6606.5 & 13355.5 & 9640.1 & 6629.1 & 13528.4 & 0.62\end{array}$

$\begin{array}{llllllll}\text { Both } & 10868.3 & 7618.1 & 14997.5 & 10857.5 & 7617.3 & 15023.3 & -0.10\end{array}$

$\begin{array}{llllllll}\text { Female } & 9380.1 & 6643.2 & 13020.3 & 9424.7 & 6715.6 & 13061.5 & 0.48\end{array}$

$\begin{array}{llllllll}\text { Male } & 8380.1 & 6643.2 & 13020.3 & 9424.7 & 6715.6 & 13061.5 & 0.48 \\ & 8536.0 & 6009.7 & 11901.9 & 8622.5 & 6100.7 & 11800.5 & 1.01\end{array}$

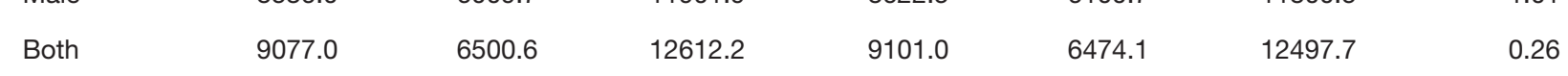

$\begin{array}{llllllll}90-94 & & & & & & & \\ \text { Female } & 6704.2 & 4852.2 & 9120.1 & 6685.5 & 4826.8 & 9016.1 & -0.28\end{array}$

$\begin{array}{llllllll}\text { Male } & 6708.8 & 4874.5 & 9115.1 & 6773.4 & 4898.3 & 9309.2 & 0.96\end{array}$

$\begin{array}{llllllll}\text { Both } & 6705.7 & 4897.9 & 9084.9 & 6715.1 & 4910.0 & 9103.8 & 0.14\end{array}$

$\begin{array}{llllllll}95+ & & & & & & & \\ \text { Female } & 5575.8 & 3897.9 & 7588.6 & 5553.6 & 3858.3 & 7511.0 & -0.40\end{array}$

\begin{tabular}{llllllll} 
Male & 5909.1 & 4177.4 & 7927.5 & 5916.3 & 4190.3 & 8032.2 & 0.12 \\
\hline
\end{tabular}

LUI, lower uncertainty interval; UUI, upper uncertainty interval. 
Table S3 The detailed information of the age-standardized prevalence rate in different provinces/regions between 1990 and 2017

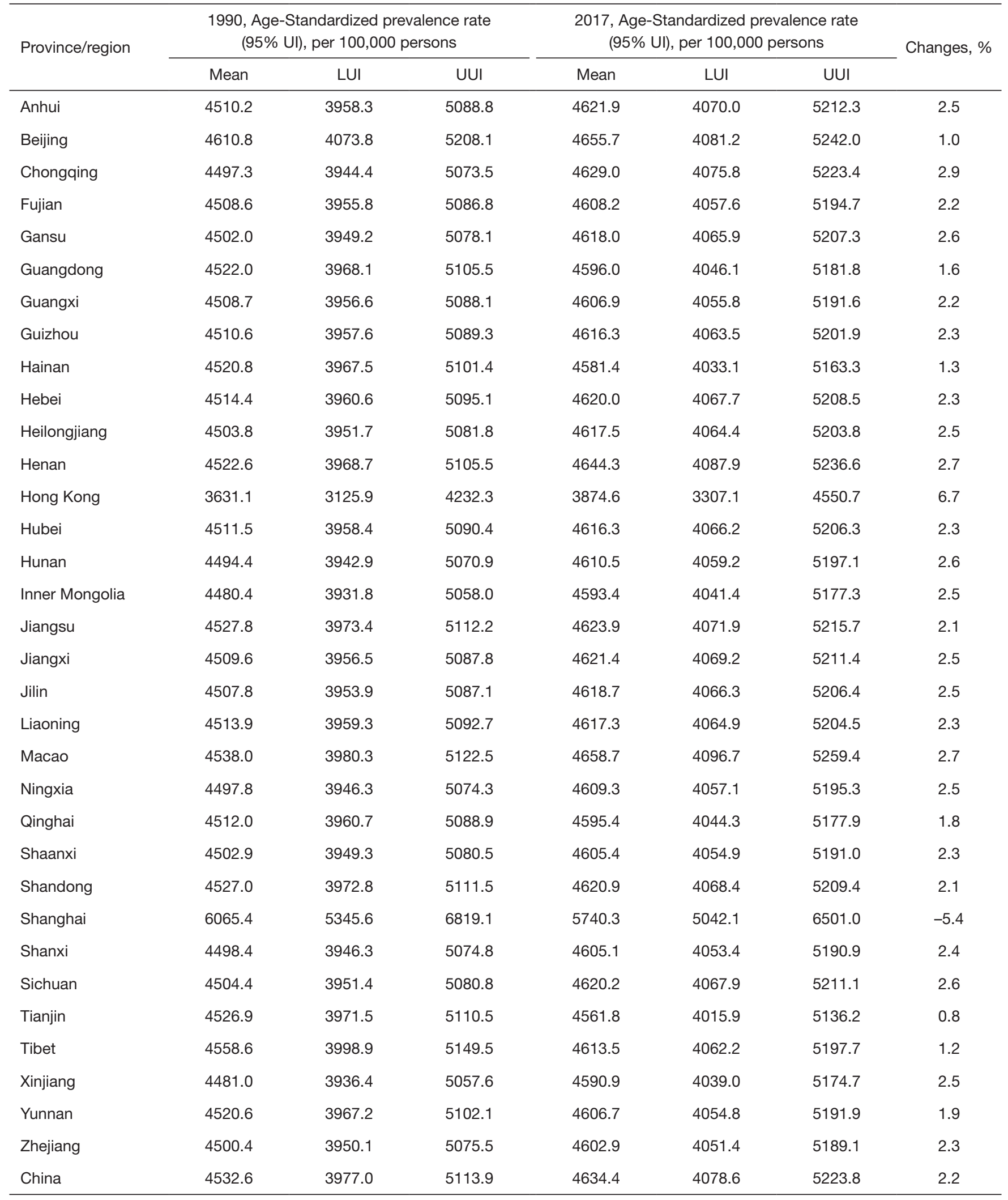

LUI, lower uncertainty interval; UUI, upper uncertainty interval. 
Table S4 The detailed information of the all age prevalent numbers in different provinces/regions between 1990 and 2017

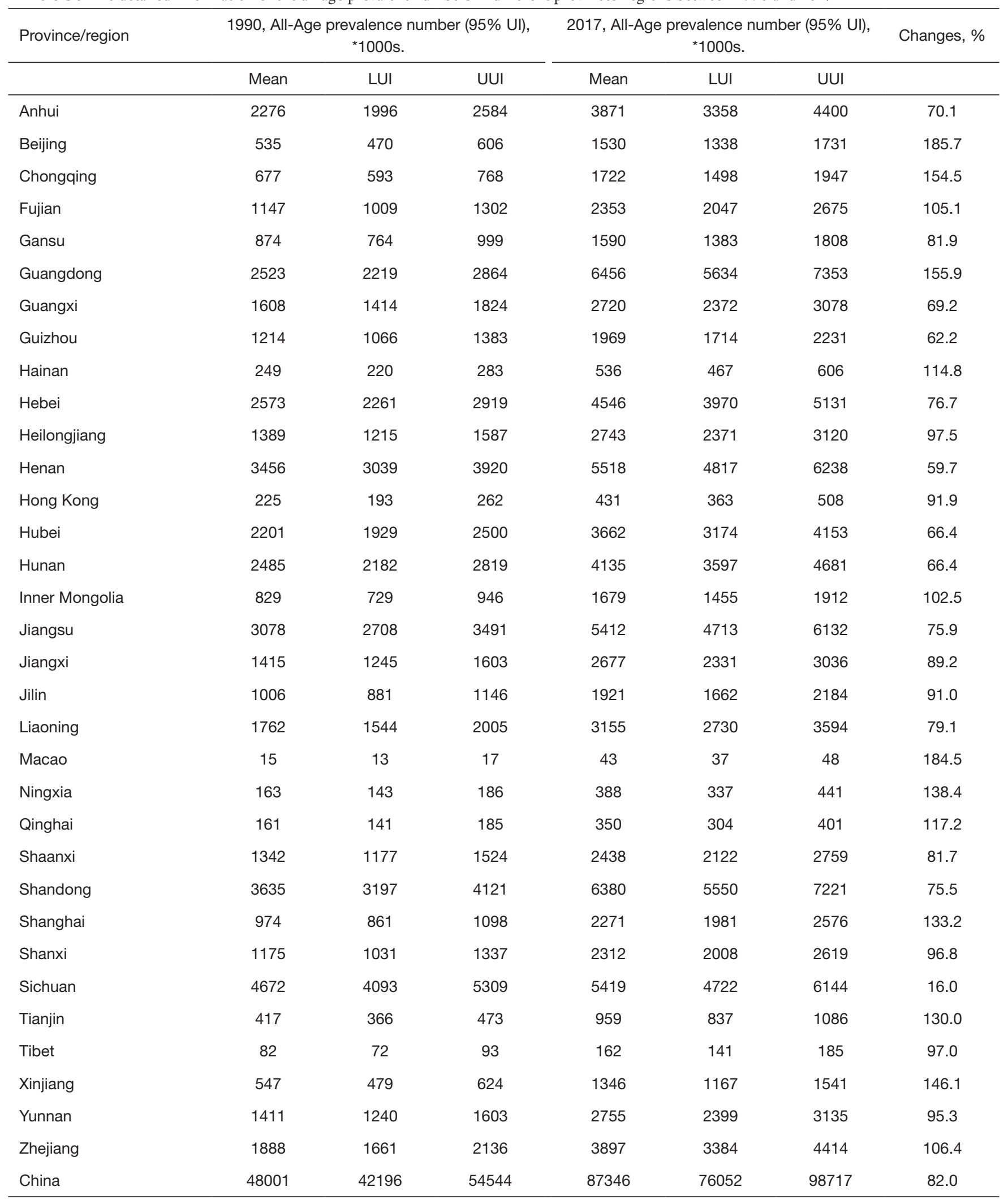

LUI, lower uncertainty interval; UUI, upper uncertainty interval. 
Table S5 The detailed information of age-standardized YLDs rate and all-age YLDs of neck pain in China from 1990 to 2017

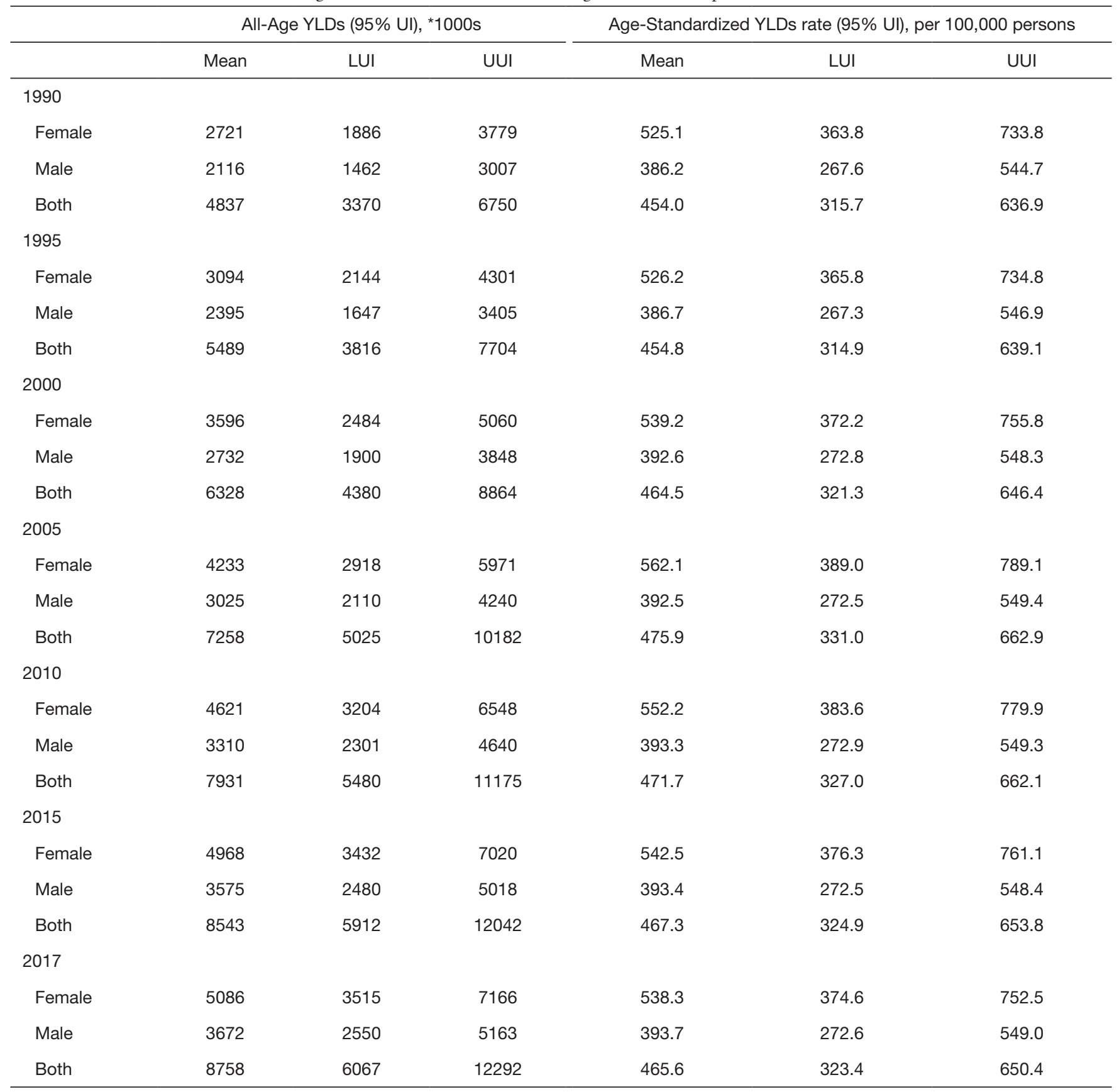




\begin{tabular}{|c|c|c|c|c|c|c|c|}
\hline \multirow{2}{*}{ Age category } & \multicolumn{3}{|c|}{ 1990, All-Age YLDs (95\% UI) } & \multicolumn{3}{|c|}{ 2017, All-Age YLDs (95\% UI) } & \multirow{2}{*}{ Changes, \% } \\
\hline & Mean & LUI & UUI & Mean & LUI & UUI & \\
\hline $0-4$ & & & & & & & \\
\hline Female & 0 & 0 & 0 & 0 & 0 & 0 & 0.0 \\
\hline Male & 0 & 0 & 0 & 0 & 0 & 0 & 0.0 \\
\hline Both & 0 & 0 & 0 & 0 & 0 & 0 & 0.0 \\
\hline $5-9$ & & & & & & & \\
\hline Female & 6150 & 3072 & 10352 & 4075 & 2147 & 6984 & -33.7 \\
\hline Male & 6823 & 3447 & 11663 & 4929 & 2523 & 8461 & -27.8 \\
\hline Both & 12973 & 6680 & 21857 & 9004 & 4665 & 15467 & -30.6 \\
\hline $10-14$ & & & & & & & \\
\hline Female & 32016 & 18464 & 51032 & 23353 & 13691 & 36842 & -27.1 \\
\hline Male & 32429 & 18375 & 50917 & 25898 & 15155 & 40641 & -20.1 \\
\hline Both & 64445 & 37476 & 101026 & 49251 & 28941 & 77810 & -23.6 \\
\hline $15-19$ & & & & & & & \\
\hline Female & 83340 & 49525 & 133180 & 53887 & 31896 & 86415 & -35.3 \\
\hline Male & 73948 & 43057 & 118260 & 51433 & 29647 & 81514 & -30.4 \\
\hline Both & 157288 & 92394 & 250672 & 105320 & 61570 & 168247 & -33.0 \\
\hline $20-24$ & & & & & & & \\
\hline Female & 147587 & 84616 & 238678 & 105184 & 61272 & 170663 & -28.7 \\
\hline Male & 122703 & 69922 & 198437 & 88916 & 49823 & 144931 & -27.5 \\
\hline Both & 270290 & 154759 & 438323 & 194100 & 110823 & 313597 & -28.2 \\
\hline 25-29 & & & & & & & \\
\hline Female & 186349 & 114278 & 288886 & 214473 & 128588 & 337018 & 15.1 \\
\hline Male & 159586 & 94176 & 249931 & 174746 & 105104 & 274625 & 9.5 \\
\hline Both & 345934 & 209397 & 536374 & 389219 & 234165 & 600283 & 12.5 \\
\hline 30-34 & & & & & & & \\
\hline Female & 208648 & 126624 & 331921 & 294264 & 178034 & 460534 & 41.0 \\
\hline Male & 189867 & 112423 & 297818 & 251634 & 153312 & 395276 & 32.5 \\
\hline Both & 398515 & 242186 & 614575 & 545898 & 329118 & 849873 & 37.0 \\
\hline 35-39 & & & & & & & \\
\hline Female & 291124 & 175498 & 461075 & 322648 & 192741 & 512753 & 10.8 \\
\hline Male & 250046 & 146361 & 401220 & 266077 & 161058 & 416695 & 6.4 \\
\hline Both & 541170 & 326258 & 853677 & 588726 & 349892 & 929514 & 8.8 \\
\hline $40-44$ & & & & & & & \\
\hline Female & 288323 & 164942 & 452681 & 505630 & 292071 & 789052 & 75.4 \\
\hline Male & 228612 & 133962 & 359731 & 376804 & 216718 & 584960 & 64.8 \\
\hline Both & 516935 & 299108 & 803869 & 882434 & 508783 & 1376330 & 70.7 \\
\hline $45-49$ & & & & & & & \\
\hline Female & 287546 & 171918 & 433859 & 742983 & 444046 & 1155726 & 158.4 \\
\hline Male & 210108 & 122841 & 322667 & 501510 & 300242 & 783327 & 138.7 \\
\hline Both & 497654 & 297400 & 754825 & 1244493 & 745552 & 1944361 & 150.1 \\
\hline 50-54 & & & & & & & \\
\hline Female & 294632 & 173664 & 446870 & 800998 & 480863 & 1214961 & 171.9 \\
\hline Male & 215165 & 126554 & 329837 & 517561 & 309589 & 794103 & 140.5 \\
\hline Both & 509797 & 302091 & 776045 & 1318559 & 798593 & 1995561 & 158.6 \\
\hline 55-59 & & & & & & & \\
\hline Female & 247657 & 153610 & 386465 & 487076 & 297856 & 754294 & 96.7 \\
\hline Male & 188347 & 115262 & 295557 & 342392 & 210473 & 531359 & 81.8 \\
\hline Both & 436005 & 272771 & 675924 & 829468 & 515097 & 1282854 & 90.2 \\
\hline $60-64$ & & & & & & & \\
\hline Female & 197900 & 118570 & 299084 & 479913 & 293297 & 723038 & 142.5 \\
\hline Male & 151093 & 91744 & 230602 & 350351 & 217507 & 535983 & 131.9 \\
\hline Both & 348994 & 213222 & 525716 & 830264 & 512767 & 1248330 & 137.9 \\
\hline $65-69$ & & & & & & & \\
\hline Female & 180775 & 109802 & 273846 & 415141 & 250123 & 624627 & 129.6 \\
\hline Male & 126721 & 75536 & 193324 & 287378 & 171589 & 439960 & 126.8 \\
\hline Both & 307496 & 187086 & 469613 & 702519 & 426110 & 1067738 & 128.5 \\
\hline $70-74$ & & & & & & & \\
\hline Female & 139625 & 89253 & 209216 & 293363 & 186241 & 443289 & 110.1 \\
\hline Male & 87468 & 55033 & 135221 & 201043 & 125245 & 311197 & 129.8 \\
\hline Both & 227093 & 143553 & 340997 & 494406 & 313734 & 750753 & 117.7 \\
\hline 75-79 & & & & & & & \\
\hline Female & 78702 & 49622 & 121964 & 179337 & 112947 & 273782 & 127.9 \\
\hline Male & 45134 & 27982 & 70806 & 125803 & 77528 & 199184 & 178.7 \\
\hline Both & 123836 & 78372 & 192003 & 305140 & 192810 & 470792 & 146.4 \\
\hline $80-84$ & & & & & & & \\
\hline Female & 37869 & 23926 & 57054 & 109695 & 68998 & 164358 & 189.7 \\
\hline Male & 20929 & 12910 & 31941 & 73484 & 45485 & 110938 & 251.1 \\
\hline Both & 58798 & 37168 & 88621 & 183179 & 115165 & 275971 & 211.5 \\
\hline $85-89$ & & & & & & & \\
\hline Female & 11184 & 6948 & 16989 & 42435 & 26172 & 65455 & 279.4 \\
\hline Male & 5773 & 3532 & 8783 & 26552 & 16175 & 40592 & 359.9 \\
\hline Both & 16957 & 10330 & 25792 & 68988 & 42259 & 105315 & 306.8 \\
\hline 90-94 & & & & & & & \\
\hline Female & 1697 & 1064 & 2556 & 9757 & 6271 & 15012 & 474.9 \\
\hline Male & 825 & 525 & 1255 & 5076 & 3233 & 7558 & 515.2 \\
\hline Both & 2522 & 1604 & 3770 & 14833 & 9500 & 22544 & 488.1 \\
\hline $95+$ & & & & & & & \\
\hline Female & 198 & 123 & 302 & 1590 & 993 & 2405 & 703.1 \\
\hline Male & 88 & 56 & 131 & 623 & 395 & 936 & 604.8 \\
\hline Both & 286 & 180 & 435 & 2212 & 1378 & 3343 & 672.7 \\
\hline
\end{tabular}

YLDs, years lived with disability; LUI, lower uncertainty interval; UUI, upper uncertainty interval. 


\begin{tabular}{|c|c|c|c|c|c|c|c|}
\hline \multirow{2}{*}{ Age category } & \multicolumn{3}{|c|}{1990 , YLDs rate $(95 \%$ UI), per 100,000 persons } & \multicolumn{3}{|c|}{2017 , YLDs rate $(95 \% \mathrm{UI})$, per 100,000 persons } & \multirow{2}{*}{ Changes, \% } \\
\hline & Mean & LUI & UUI & Mean & LUI & UUI & \\
\hline $0-4$ & & & & & & & \\
\hline Female & 0.0 & 0.0 & 0.0 & 0.0 & 0.0 & 0.0 & 0.0 \\
\hline Male & 0.0 & 0.0 & 0.0 & 0.0 & 0.0 & 0.0 & 0.0 \\
\hline Both & 0.0 & 0.0 & 0.0 & 0.0 & 0.0 & 0.0 & 0.0 \\
\hline $5-9$ & & & & & & & \\
\hline Female & 12.2 & 6.1 & 20.5 & 12.4 & 6.5 & 21.2 & 1.4 \\
\hline Male & 12.5 & 6.3 & 21.4 & 12.6 & 6.4 & 21.6 & 0.6 \\
\hline Both & 12.4 & 6.4 & 20.8 & 12.5 & 6.5 & 21.4 & 1.0 \\
\hline $10-14$ & & & & & & & \\
\hline Female & 64.6 & 37.3 & 103.0 & 69.4 & 40.7 & 109.5 & 7.4 \\
\hline Male & 61.3 & 34.8 & 96.3 & 65.1 & 38.1 & 102.1 & 6.1 \\
\hline Both & 62.9 & 36.6 & 98.6 & 67.0 & 39.4 & 105.9 & 6.6 \\
\hline $15-19$ & & & & & & & \\
\hline Female & 134.9 & 80.1 & 215.5 & 149.5 & 88.5 & 239.8 & 10.9 \\
\hline Male & 113.4 & 66.0 & 181.3 & 125.7 & 72.5 & 199.2 & 10.9 \\
\hline Both & 123.8 & 72.7 & 197.3 & 136.9 & 80.0 & 218.6 & 10.5 \\
\hline $20-24$ & & & & & & & \\
\hline Female & 228.4 & 131.0 & 369.4 & 237.9 & 138.6 & 386.0 & 4.1 \\
\hline Male & 181.6 & 103.5 & 293.6 & 187.5 & 105.1 & 305.6 & 3.3 \\
\hline Both & 204.5 & 117.1 & 331.6 & 211.8 & 120.9 & 342.2 & 3.6 \\
\hline $25-29$ & & & & & & & \\
\hline Female & 347.7 & 213.2 & 539.1 & 351.8 & 210.9 & 552.8 & 1.2 \\
\hline Male & 282.0 & 166.4 & 441.7 & 281.7 & 169.5 & 442.8 & -0.1 \\
\hline Both & 314.0 & 190.1 & 486.8 & 316.4 & 190.4 & 488.1 & 0.8 \\
\hline 30-34 & & & & & & & \\
\hline Female & 493.8 & 299.7 & 785.6 & 499.8 & 302.4 & 782.2 & 1.2 \\
\hline Male & 411.8 & 243.8 & 645.9 & 416.1 & 253.5 & 653.7 & 1.1 \\
\hline Both & 451.0 & 274.1 & 695.5 & 457.4 & 275.8 & 712.1 & 1.4 \\
\hline 35-39 & & & & & & & \\
\hline Female & 658.8 & 397.1 & 1043.4 & 675.1 & 403.3 & 1072.9 & 2.5 \\
\hline Male & 528.2 & 309.1 & 847.5 & 536.8 & 324.9 & 840.7 & 1.6 \\
\hline Both & 591.2 & 356.4 & 932.6 & 604.7 & 359.4 & 954.8 & 2.3 \\
\hline $40-44$ & & & & & & & \\
\hline Female & 901.6 & 515.8 & 1415.5 & 929.6 & 536.9 & 1450.6 & 3.1 \\
\hline Male & 648.3 & 379.9 & 1020.2 & 667.9 & 384.1 & 1036.8 & 3.0 \\
\hline Both & 768.8 & 444.8 & 1195.5 & 796.3 & 459.1 & 1242.0 & 3.6 \\
\hline $45-49$ & & & & & & & \\
\hline Female & 1177.5 & 704.0 & 1776.6 & 1212.3 & 724.6 & 1885.8 & 3.0 \\
\hline Male & 770.1 & 450.2 & 1182.6 & 789.0 & 472.3 & 1232.3 & 2.5 \\
\hline Both & 962.5 & 575.2 & 1459.9 & 996.8 & 597.2 & 1557.3 & 3.6 \\
\hline $50-54$ & & & & & & & \\
\hline Female & 1309.8 & 772.0 & 1986.6 & 1346.3 & 808.2 & 2042.1 & 2.8 \\
\hline Male & 850.4 & 500.2 & 1303.6 & 862.7 & 516.1 & 1323.7 & 1.5 \\
\hline Both & 1066.6 & 632.0 & 1623.6 & 1103.5 & 668.4 & 1670.1 & 3.5 \\
\hline $55-59$ & & & & & & & \\
\hline Female & 1197.6 & 742.8 & 1868.8 & 1222.3 & 747.4 & 1892.8 & 2.1 \\
\hline Male & 826.9 & 506.0 & 1297.6 & 841.2 & 517.1 & 1305.5 & 1.7 \\
\hline Both & 1003.3 & 627.7 & 1555.4 & 1029.7 & 639.5 & 1592.6 & 2.6 \\
\hline $60-64$ & & & & & & & \\
\hline Female & 1151.4 & 689.9 & 1740.1 & 1163.3 & 710.9 & 1752.6 & 1.0 \\
\hline Male & 827.5 & 502.5 & 1263.0 & 843.6 & 523.7 & 1290.6 & 1.9 \\
\hline Both & 984.6 & 601.5 & 1483.1 & 1002.9 & 619.4 & 1507.9 & 1.9 \\
\hline $65-69$ & & & & & & & \\
\hline Female & 1300.0 & 789.6 & 1969.3 & 1336.2 & 805.1 & 2010.5 & 2.8 \\
\hline Male & 941.2 & 561.1 & 1436.0 & 953.4 & 569.3 & 1459.6 & 1.3 \\
\hline Both & 1123.5 & 683.6 & 1715.9 & 1147.7 & 696.1 & 1744.4 & 2.2 \\
\hline $70-74$ & & & & & & & \\
\hline Female & 1380.6 & 882.5 & 2068.8 & 1409.6 & 894.9 & 2130.0 & 2.1 \\
\hline Male & 999.8 & 629.0 & 1545.6 & 1008.0 & 628.0 & 1560.3 & 0.8 \\
\hline Both & 1204.0 & 761.1 & 1807.9 & 1213.1 & 769.8 & 1842.1 & 0.8 \\
\hline $75-79$ & & & & & & & \\
\hline Female & 1211.1 & 763.6 & 1876.8 & 1225.5 & 771.8 & 1870.9 & 1.2 \\
\hline Male & 916.8 & 568.4 & 1438.2 & 924.4 & 569.7 & 1463.6 & 0.8 \\
\hline Both & 1084.2 & 686.2 & 1681.0 & 1080.4 & 682.7 & 1666.9 & -0.4 \\
\hline $80-84$ & & & & & & & \\
\hline Female & 1080.4 & 682.6 & 1627.8 & 1091.5 & 686.6 & 1635.4 & 1.0 \\
\hline Male & 893.8 & 551.4 & 1364.2 & 897.9 & 555.8 & 1355.6 & 0.5 \\
\hline Both & 1005.7 & 635.7 & 1515.8 & 1004.6 & 631.6 & 1513.5 & -0.1 \\
\hline $85-89$ & & & & & & & \\
\hline Female & 849.7 & 527.8 & 1290.7 & 852.6 & 525.8 & 1315.1 & 0.3 \\
\hline Male & 782.8 & 479.0 & 1191.0 & 788.7 & 480.4 & 1205.7 & 0.7 \\
\hline Both & 825.7 & 503.0 & 1255.8 & 826.8 & 506.5 & 1262.2 & 0.1 \\
\hline $90-94$ & & & & & & & \\
\hline Female & 596.6 & 374.1 & 898.5 & 594.8 & 382.3 & 915.1 & -0.3 \\
\hline Male & 605.4 & 385.1 & 921.1 & 609.4 & 388.1 & 907.5 & 0.7 \\
\hline Both & 599.4 & 381.2 & 895.9 & 599.7 & 384.1 & 911.5 & 0.0 \\
\hline $95+$ & & & & & & & \\
\hline Female & 488.9 & 303.7 & 746.0 & 487.2 & 304.4 & 737.3 & -0.3 \\
\hline Male & 524.8 & 331.0 & 779.8 & 525.3 & 333.4 & 789.6 & 0.1 \\
\hline Both & 499.5 & 313.4 & 758.4 & 497.4 & 309.8 & 751.6 & -0.4 \\
\hline
\end{tabular}

YLDs, years lived with disability; LUI, lower uncertainty interval; UUI, upper uncertainty interval. 
Table S8 The detailed information of age standardized YLDs rate of different provinces/regions between 1990 and 2017

\begin{tabular}{|c|c|c|c|c|c|c|c|}
\hline \multirow{2}{*}{ Province/region } & \multicolumn{3}{|c|}{$\begin{array}{c}\text { 1990, age standardized YLDs rate, per 100,000 } \\
\text { persons. }\end{array}$} & \multicolumn{3}{|c|}{$\begin{array}{c}\text { 2017, age standardized YLDs rate, per 100,000 } \\
\text { persons. }\end{array}$} & \multirow{2}{*}{ Changes, \% } \\
\hline & Mean & LUI & UUI & Mean & LUI & UUI & \\
\hline Beijing & 462.2 & 320.4 & 651.5 & 466.9 & 323.7 & 651.4 & 1.0 \\
\hline Chongqing & 450.3 & 314.2 & 636.4 & 465.6 & 324.3 & 648.5 & 3.4 \\
\hline Gansu & 449.6 & 312.5 & 631.6 & 463.9 & 322.4 & 648.8 & 3.2 \\
\hline Guangdong & 452.8 & 314.5 & 634.9 & 461.0 & 320.7 & 641.6 & 1.8 \\
\hline Guangxi & 451.7 & 314.1 & 631.6 & 463.7 & 321.1 & 648.2 & 2.7 \\
\hline Heilongjiang & 450.4 & 313.6 & 633.4 & 463.3 & 321.8 & 644.8 & 2.9 \\
\hline Henan & 453.8 & 316.3 & 636.9 & 466.9 & 325.0 & 651.5 & 2.9 \\
\hline Hong Kong & 366.6 & 248.2 & 524.0 & 390.7 & 262.9 & 559.1 & 6.5 \\
\hline Hubei & 450.3 & 312.9 & 631.3 & 462.3 & 320.9 & 641.0 & 2.7 \\
\hline Hunan & 450.1 & 313.4 & 631.7 & 463.7 & 321.9 & 647.6 & 3.0 \\
\hline Inner Mongolia & 449.2 & 311.7 & 630.8 & 461.7 & 320.0 & 645.4 & 2.8 \\
\hline Jiangsu & 453.2 & 313.8 & 639.1 & 464.2 & 323.5 & 647.3 & 2.4 \\
\hline Qinghai & 452.8 & 313.6 & 634.3 & 462.5 & 322.2 & 645.7 & 2.2 \\
\hline Shaanxi & 453.0 & 314.2 & 637.0 & 463.5 & 322.0 & 649.0 & 2.3 \\
\hline Shandong & 454.0 & 316.0 & 635.7 & 464.7 & 322.7 & 649.7 & 2.4 \\
\hline Shanghai & 606.6 & 422.6 & 850.8 & 576.3 & 398.1 & 804.2 & -5.0 \\
\hline Shanxi & 450.8 & 313.2 & 632.1 & 463.2 & 323.9 & 642.9 & 2.8 \\
\hline Sichuan & 451.2 & 313.7 & 633.7 & 463.6 & 322.7 & 646.8 & 2.8 \\
\hline Tianjin & 454.8 & 316.3 & 638.3 & 458.8 & 319.3 & 641.2 & 0.9 \\
\hline Tibet & 455.3 & 316.3 & 638.8 & 463.6 & 321.3 & 646.9 & 1.8 \\
\hline Xinjiang & 450.1 & 312.3 & 631.7 & 461.7 & 321.4 & 646.4 & 2.6 \\
\hline Yunnan & 452.1 & 313.3 & 636.8 & 462.4 & 322.2 & 644.9 & 2.3 \\
\hline Zhejiang & 449.6 & 312.3 & 629.6 & 462.9 & 321.7 & 648.1 & 3.0 \\
\hline China & 454.0 & 315.7 & 636.9 & 465.6 & 323.4 & 650.4 & 2.6 \\
\hline
\end{tabular}

YLDs, years lived with disability; LUI, lower uncertainty interval; UUI, upper uncertainty interval. 
Table S9 The detailed information of the all age YLDs of different provinces/regions between 1990 and 2017

\begin{tabular}{|c|c|c|c|c|c|c|c|}
\hline Province/region & \multicolumn{3}{|c|}{1990 All-Age YLDs (95\% UI), *1000s. } & \multicolumn{3}{|c|}{2017 All-Age YLDs (95\% UI), *1000s. } & Changes, $\%$ \\
\hline Anhui & 229 & 159 & 322 & 387 & 267 & 543 & 69.2 \\
\hline Beijing & 54 & 37 & 76 & 153 & 106 & 217 & 184.3 \\
\hline Chongqing & 68 & 47 & 96 & 172 & 119 & 240 & 152.2 \\
\hline Gansu & 88 & 61 & 124 & 160 & 110 & 225 & 81.1 \\
\hline Guangdong & 254 & 177 & 358 & 649 & 452 & 915 & 155.7 \\
\hline Guangxi & 162 & 112 & 226 & 273 & 189 & 383 & 68.7 \\
\hline Guizhou & 122 & 85 & 170 & 197 & 137 & 276 & 61.6 \\
\hline Heilongjiang & 140 & 98 & 197 & 275 & 190 & 390 & 95.7 \\
\hline Henan & 349 & 243 & 488 & 554 & 385 & 782 & 58.9 \\
\hline Hong Kong & 23 & 15 & 33 & 43 & 29 & 62 & 89.8 \\
\hline Hubei & 221 & 154 & 309 & 366 & 253 & 511 & 65.3 \\
\hline Hunan & 250 & 174 & 350 & 415 & 285 & 583 & 65.7 \\
\hline Inner Mongolia & 84 & 58 & 118 & 169 & 117 & 239 & 101.1 \\
\hline Jiangsu & 309 & 214 & 435 & 541 & 375 & 759 & 74.7 \\
\hline Jiangxi & 142 & 99 & 197 & 269 & 188 & 379 & 89.1 \\
\hline Shaanxi & 136 & 94 & 190 & 245 & 171 & 346 & 80.5 \\
\hline Shandong & 366 & 255 & 512 & 639 & 442 & 901 & 74.5 \\
\hline Shanghai & 97 & 68 & 137 & 227 & 158 & 318 & 133.3 \\
\hline Shanxi & 118 & 83 & 166 & 232 & 162 & 326 & 96.2 \\
\hline Sichuan & 471 & 328 & 661 & 541 & 375 & 754 & 15.0 \\
\hline Tianjin & 42 & 29 & 59 & 96 & 67 & 135 & 129.0 \\
\hline Tibet & 8 & 6 & 12 & 16 & 11 & 23 & 98.2 \\
\hline Xinjiang & 55 & 38 & 78 & 136 & 94 & 193 & 145.0 \\
\hline Yunnan & 142 & 98 & 200 & 277 & 192 & 391 & 94.8 \\
\hline Zhejiang & 189 & 132 & 263 & 391 & 270 & 553 & 106.5 \\
\hline China & 4837 & 3370 & 6750 & 8758 & 6067 & 12292 & 81.1 \\
\hline
\end{tabular}

YLDs, years lived with disability; LUI, lower uncertainty interval; UUI, upper uncertainty interval. 